\title{
CONTINUITY OF MIDWIFERY CARE IN COMPLEXITY
}

\section{A QUALITATIVE DESCRIPTION}

by

Eleanor Mary Martin

A thesis submitted to the Victoria University of Wellington

In fulfilment of the requirements for the degree of

Master of Health Science

Victoria University of Wellington

2019 


\section{Abstract}

Continuity of midwifery care has demonstrated some beneficial outcomes for mothers and their babies with no evidence of poorer outcomes. Much of the evidence to support this claim is sourced from research conducted with women described as 'low risk'. The model of midwifery in New Zealand, which is based on continuity of midwifery carer, has the potential for midwives to continue care even when significant risk has been identified. This care would be provided in collaboration with and support from medical personnel and hospital-based midwives. There is no research that has specifically examined the outcomes for women with complex needs, also called 'high risk', who have been provided continuity of midwifery carer. Given the increased incidence of morbidity in the childbearing population it is important to examine this issue in some depth. This small piece of research begins this, by looking at how women with complex needs and who have had continuity of midwifery care have experienced this care.

The aim of this research therefore is to provide a comprehensive description of how women with complexities experience continuity of midwifery care across the maternity episode.

A qualitative descriptive study was conducted in one part of New Zealand. Three women, all with varying types of complexity were interviewed. The interviews were transcribed, and the transcripts were analysed thematically. There were four themes: the relationship was everything; knowing what was happening was important; power was managed and balanced; and extra care was needed. The three women had the same needs and experiences of continuity as did low risk women described in the literature. However, another aspect, not previously reported, was that the women thought that the midwives spent a lot more time with them than they otherwise would have needed to. They were very grateful for this. 


\section{Acknowledgments}

Thank you to all the women who I have walked alongside on their path to motherhood. It has been a privilege.

Thank you to my supervisor Joan Skinner for her availability and words of wisdom.

Thank you to my midwifery colleagues going back many years; not only for midwifery support but editing, formatting and listening.

I dedicate this to my beloved family; my parents and to the wonderful tribe they created. I especially want to acknowledge our new generation being born; Madi, Annabelle, Freddy, Carter, Florence, Amelia, and Benjamin. 


\section{Table of Contents}

Abstract

Acknowledgments ii

Table of Contents iii

Chapter 1: Introduction 1

$\begin{array}{ll}\text { Background } & 2\end{array}$

Continuity of care $\quad 2$

Context of the study 3

Risk and complexity $\quad 5$

$\begin{array}{ll}\text { The aim and objectives } & 8\end{array}$

$\begin{array}{lr}\text { My story } & 9\end{array}$

$\begin{array}{lr}\text { Thesis outline } & 10\end{array}$

$\begin{array}{ll}\text { Chapter 2: Literature Review } & 12\end{array}$

$\begin{array}{ll}\text { Continuity of care } & 13\end{array}$

$\begin{array}{ll}\text { Types of midwifery continuity models } & 14\end{array}$

Outcomes of midwifery led continuity models of care 19

$\begin{array}{ll}\text { Women with Social Complexity } & 22\end{array}$

Importance of relationship within a continuity of care framework 23

High risk women's experience of discontinuity of care 25

$\begin{array}{ll}\text { Summary } & 27\end{array}$

Chapter 3: Methodology and Design 28

$\begin{array}{ll}\text { Introduction } & 28\end{array}$

$\begin{array}{ll}\text { Choice of research approach } & 28\end{array}$

$\begin{array}{ll}\text { Qualitative description } & 30\end{array}$

$\begin{array}{ll}\text { Interview as chosen method } & 31\end{array}$

$\begin{array}{ll}\text { Recruitment } & 31\end{array}$

$\begin{array}{ll}\text { The interviews } & 33\end{array}$ 
Data Analysis

Treaty of Waitangi

Ethical consideration

Rigour

Summary

$\begin{array}{ll}\text { Chapter 4: Findings } & 41\end{array}$

$\begin{array}{ll}\text { Description of participants } & 41\end{array}$

$\begin{array}{ll}\text { Heather's Story } & 41\end{array}$

$\begin{array}{ll}\text { Kate's Story } & 42\end{array}$

$\begin{array}{ll}\text { Felicity's Story } & 43\end{array}$

$\begin{array}{ll}\text { Themes } & 44\end{array}$

$\begin{array}{ll}\text { The relationship was everything } & 44\end{array}$

$\begin{array}{ll}\text { Having mutual trust and respect } & 44\end{array}$

Grateful for the care $\quad 45$

$\begin{array}{ll}\text { Feeling comfortable and close } & 46\end{array}$

A calm and composed midwife 46

$\begin{array}{ll}\text { Appreciated the midwife } & 47\end{array}$

$\begin{array}{ll}\text { Knowing what was happening was important } & 47\end{array}$

$\begin{array}{ll}\text { Clarifying the midwifery role } & 47\end{array}$

$\begin{array}{ll}\text { Interpreting medical information } & 48\end{array}$

$\begin{array}{ll}\text { Listening and teaching } & 49\end{array}$

$\begin{array}{ll}\text { She had the big picture } & 50\end{array}$

Power was managed and balanced 51

$\begin{array}{ll}\text { Being empowering and uplifting } & 51\end{array}$

Advocating 51

$\begin{array}{lr}\text { Sharing decision making } & 52\end{array}$

Extra care was needed 53 
She was always there

The midwife relieves fear and anxiety $\quad 54$

Managing the three-way consultations and the information 55

Summary $\quad 55$

$\begin{array}{ll}\text { Chapter 5: Discussion } & 57\end{array}$

$\begin{array}{ll}\text { The themes and the literature } & 57\end{array}$

$\begin{array}{ll}\text { The relationship is everything } & 57\end{array}$

Knowing what was happening was important 58

Power was managed and balanced. 59

$\begin{array}{ll}\text { Extra midwifery care was needed } & 59\end{array}$

$\begin{array}{ll}\text { Key messages from the research } & 60\end{array}$

Continuity is even more important where complexity increases $\quad 60$

The woman defines the complexity; the midwife becomes the central $\begin{array}{ll}\text { holder of that interpretation } & 61\end{array}$

Separating off women who can and cannot have midwifery continuity is $\begin{array}{ll}\text { problematic } & 62\end{array}$

$\begin{array}{ll}\text { Reflections on the research process } & 63\end{array}$

$\begin{array}{ll}\text { Suggestions } & 64\end{array}$

$\begin{array}{ll}\text { Concluding statement } & 64\end{array}$

$\begin{array}{ll}\text { Appendix A } & 66\end{array}$

$\begin{array}{ll}\text { Appendix B } & 67\end{array}$

$\begin{array}{ll}\text { Appendix C } & 69\end{array}$

$\begin{array}{ll}\text { Appendix D } & 71\end{array}$

$\begin{array}{ll}\text { Appendix E } & 72\end{array}$

$\begin{array}{ll}\text { References } & 74\end{array}$ 


\section{Chapter 1: Introduction}

The success of continuity of midwifery care in low risk pregnancy has been widely explored in the literature. What is less clear is whether continuity of midwifery care makes a difference to women who develop complexity during their pregnancies or who have existing medical conditions (Sandall, Soltani, Gates, Shennan, \& Devane, 2016; Tracy et al., 2013). The phrase 'continuity of care' is often cited as contributing to high quality maternity care (Sandall et al., 2016; Wickham, 2015). However it is not well-defined as a concept and can be taken to apply to a number of different ways of providing care. In New Zealand continuity of care means "one midwife (and her backup colleague) providing midwifery care throughout the entire childbirth experience" (Guilliland, \& Pairman, 1995, P.39).

What we do know is that continuity of caregiver during low risk pregnancy, labour and birth has been demonstrated to improve certain measurable outcomes, and not increase risks, for mother and baby (Miller,\& Bear, 2019; Pairman, \& McAra- Couper, 2015; Sandall et al., 2016). The success of this approach is also reflected in women's reported satisfaction with their experience of care (Davis, \& Hunter, 2015; Miller, \& Wilkes, 2015).

However, the number of women who experience a complex pregnancy is rising and these women are more likely to experience worry, anxiety, unease, inequity and adverse outcomes (Donnellan-Fernandez, Creedy, \& Callander, 2018). There is evidence from Dutch studies that these women, who have higher risk during their maternity episode, are more likely to experience fragmented care, poor communication and mislaid information, as more practitioners become involved in their care (de Jonge, Stuijt, Eijke, \& Westerman, 2014; Perdok et al., 2016).

Continuity of care is patient orientated, and not system based, so there is potential for a breakdown in continuity of care when it comes into contact with the hospital system (Brand \& Pollock, 2018). de Jonge and colleagues interviewed women on their experience of transfer of midwifery care from their known primary midwife to a hospital midwife when complexity developed during labour. The women expressed a negative birth experience based on handover 
of care, they felt unsafe with the change of their known primary midwife to a hospital midwife (de Jonge et al., 2014). Outside of the maternity system, Brand and Pollock (2018) interviewed 13 patients with end stage renal disease about their experience of continuity of care. One of the key findings was that the presence of the carer that they had formed a relationship with was central to their feeling of safety when unexpected or acute deterioration occurred.

My study starts the conversation with women who have had continuity of midwifery care where there is complexity, to find out how they experienced this. There have been questions raised about whether continuity of care is valued equally by women in this group. As continuity of care is from the perspective of the woman's experience, it is important that we ask women with complex pregnancies about their experience.

\section{Background}

\section{Continuity of care}

As background to the study I will introduce the concept and the emergence of continuity of care and my experience of providing it. Continuity of care has been of interest in the wider aspects of health for a number of years (Wickham, 2015). The World Health Organization in the Ottawa charter 1986 identified continuity of care as a key action for good health promotion as it allows for integration across the three levels of care: primary, secondary and tertiary. It had the vision for continuous care from the community right through the different levels of the hospital systems. However, once the patient comes into contact with the hospital system there is a potential for loss of continuity. The charter endorsed continuity of midwifery care in their model of primary health care in the 1970s (Thorogood, 2015). Continuity of care has been around a long time and has evolved into having different meanings. It became a concept which was poorly explained and vague. Hence continuity of care needs an explanation of what it means in the context in which it is used (Freeman et al., 2007).

Haggerty et al., (2003) instigated a review on the meaning of continuity of care to clarify the concept and distinguish it from the continuum of care, coordination 
of care and discharge planning. A second source of confusion about continuity of care is the distinction between continuity of care and continuity of carer. Haggerty et al., note that continuity of care is different from other similar strategies of care by two specific features. The first being a relationship between the health practitioner and the patient/woman. The second element is that the care continues over a period of time. This understanding of continuity of care is particularly important for maternity. As pregnancy is a specific time period, continuity eliminates many people giving different information and encourages a relationship to develop over time forming trust between caregiver and the woman (Jenkins et al., 2015). Consequently, this has become a desired component of a midwifery service in parts of the world. Haggerty et al., propose that continuity of care belongs in the primary health sector. This is reflected in current midwifery literature. Continuity of care is a key component of the partnership midwifery model, which sits within the primary health service in recognition that birth is a normal life event. Further, Haggarty et al. note that there are three types of continuity of care: relational, management and informational. They conclude that all three aspects contribute to better care and better patient experience. Continuity of care is a complex intervention as there are many variants of continuity of care in midwifery models and different ways that it is represented in practice (Sandall et al., 2016). Which one is useful, is a matter for research. The demand for a continuity of care midwifery model was heard from both the women and midwifery voice which introduces the next section.

\section{Context of the study}

In the late eighties the maternity consumer groups, together with the midwives, negotiated with the government at the time to introduce a partnership model of care. Women wanted continuity of care as they wanted a known midwife to be with them throughout their childbirth experience (Association of Midwives, 1986). In New Zealand midwives introduced continuity of midwifery care as the key underpinning of the partnership midwifery model (Pairman \& McAraCouper, 2015). This has since been embedded in practice. The current national model of maternity care in New Zealand is based on partnership and continuity of carer with legislated regulation around it. This model was strategically 
developed so that the relationship between a woman and midwife had time to develop trust and integrity as the fundamental instrument of care (Kennedy, Shannon, Chuahorm, \& Kravetz, 2004; Miller, \& Wilkes, 2015). Continuity of carer means 'one midwife (and her backup colleague) providing midwifery care throughout the entire childbirth experience' (Pairman \& McAra- Couper, 2015). Most women will receive all care by their named midwife. There are however guidelines for Consultation with Obstetric and Related Medical Services (Referral Guidelines) (Ministry of Health, 2012) in place to assist midwives in offering a referral for the woman when her condition requires input outside of the midwifery scope of practice (Miller, \& Dahlen, 2019).These guidelines enable a community midwife to work in collaboration with other health professionals while providing midwifery care. For women who have pre-existing or develop clinical complexities there is the option of obstetric led care where continuity of midwifery care is negotiable. Midwifery care can also be transferred to secondary or tertiary services (Ministry of Health, 2012). The legislation provides midwives with the option to continue care through the existing frameworks for all women. It does not provide the option of handing over midwifery care for women with social complexity.

Community midwives provide care both in the community and in the hospital environment. Such integration is not usual in other primary health care practices. Midwives need an understanding of both environments to work in them. One of the frameworks that supports this is the National Access Agreement (Eddy, \& Campbell, 2019). This enables midwives to provide care for their clients across all levels of care from the primary to the tertiary level, thus supporting ongoing care in complexity. However, in practice this is challenging. Public hospital obstetric services are not structured to provide women with access to continuity of care and, for women who already have a community midwife, the nature of this relationship might be significantly altered by the development of clinical complexity (Skinner, 2011). Midwives may be discouraged by other health professionals from continuing to be involved in the woman's care, or may be disinclined to do so. It is unknown, at this time, the degree to which women experiencing complexity have the opportunity to choose continued input from a community midwife. 


\section{Risk and complexity}

I have thought long and hard about the implications of using the term 'risk' or 'complexity' when a woman's status changes and she requires additional care from other practitioners. In current literature these two concepts often have the same meaning but with a slightly different connotation. Complexity has two distinct meanings. The first being that medical and obstetric conditions can be described as complex. Donnellan-Fernandez et al. (2018) define complexity in pregnancy as identified clinical and/or psychosocial risks which place the mother and baby in situations more likely to have poorer outcomes.

Simultaneously the Ministry of Health (2019) classify maternity services according to the level of complexity of clinical care a woman and her baby require - either primary, secondary or tertiary. The second meaning of complexity refers to complexity theory and how complex systems work. The maternity experience is influenced by many factors which are unpredictable (Enkin, 2006; Skinner \& Maude, 2015). Enkin states that the outcome is no longer seen as controlled by cause and effect but in the complex interrelationships between the woman, the system, the policies, the context, and the health professional providing care. Skinner and Dahlen (2015) concur and state that "Working alongside women things are often complex and unclear" (p.96). It is within the messiness of practice in which complexity both medical, social and environmental is identified. Complexity system accepts uncertainty as a normal part of the outcome, while risk demands the expectation that it can be controlled or avoided and therefore the outcome is expected to be normal. Complete safety can never be assured, complexity and its acknowledgement of uncertainty is more useful to use. Skinner (2003) and Enkin both agree that complexity is to accept the uncertainty of an outcome and the "uncomfortable reality that there are no comprehensive formulas" (p.268). All women need a midwife and some women need additional care from a range of specialities (Sandall, Coxon, Mackintosh, Rayment-Jones \& Page, 2016). So in this sense every childbearing women is complex.

I have chosen to use the former definition for pragmatic reasons. I do wish the reader to understand however that underlying this understanding is the idea, ever present for midwives, that the whole experience is unpredictable. The 
notion of complexity in this research addresses the continuum of the experience and includes both clinical and social aspects of risk and the environment. Women with complexities will exercise autonomy in decision making. The term 'complex needs' involves a continuum of obstetric risks, and when planning care for these women the health professional's thoughts about 'risk' may be at odds with the perception and acceptability of risk for women. Women often describe their own risk factors, as much as their health professionals will, and at times these will be different. (Donnellan-Fernandez, Creedy \& Callander, 2018). There is also no consensus of the definition of high risk in the wider literature (Lee, Ayers, \& Holden, 2015). I was interested in seeing if and how this issue emerged

Midwifery is holistic in nature. Using only a clinical risk structure i.e. either low or high risk, thus missing social complex situations, can preclude identifying issues impacting on the provision of safe quality care. For the purpose of this study then I included both clinical and social complexity because they are interrelated. I have defined clinical complexity in line with the New Zealand Maternity services classifications - when a woman's pregnancy, birth or the postpartum period is complicated by a condition which is considered an indication for transfer of clinical responsibility to obstetric services, as per Guidelines for Consultation with Obstetric and Related Medical Services (Referral Guidelines) (Ministry of Health, 2012). The Obstetric service leads the clinical decisions.

In the New Zealand context social complexity is not defined, rather the term vulnerable women is used (Ministry of Health, 2019a). There is however no agreed definition of a vulnerable mother and/or her child (Ministry for Women, 2018). Briscoe, Lavender, \& McGowan (2016) describe 'vulnerability' as a complex phenomenon in pregnancy. There is, however, agreement on the risk factors that can contribute to vulnerability. These risks relate to the mother's situation, the home environment and issues relating to the pregnancy, birth and postnatal care. I have used the definition of vulnerability that Morton et al. (2014) Morton et al. suggested from their 'Growing up in New Zealand' study (GUNZ). Throughout their study they explored the definition of vulnerability for children in their First 1000 Days and from that research grouped the risks 
together to define the vulnerable woman. These are: "young, single mothers, without formal educational qualifications, who are likely to continue smoking in pregnancy and be in receipt of an income-tested benefit; mothers who are living in areas of high deprivation, in overcrowded, rental housing; mothers experiencing high levels of physical, emotional and/or financial stress during late pregnancy or during the postnatal period" (p.20). These vulnerable women will be more likely to have clinical complexity such as foetal growth restriction (Beake, Acosta, Cooke, \& McCourt, 2013; C. S. Homer, Leap, Edwards, \& Sandall, 2017; Rayment-Jones, Murrells, \& Sandall, 2015). They may have poor understanding about pregnancy and the care that is available, much of it being anecdotal from their friends or families. Evidence shows poorer outcomes and inequity of care for women with complex pregnancies as they may be unable to negotiate the steps to find an appropriate or suitable midwife (Donnellan-Fernandez et al., 2018). It would seem logical that these mothers would need long term community midwives that they can get to know.

There is growing body of evidence of increasing numbers of women experiencing complexity in their maternity episode, with multiple strands of clinical, psychological and social stressors. This is reflected in Australia (Donnellan-Fernandez et al., 2018) and the Netherlands (Perdok et al., 2014) and globally (Daly, Raiman, \& Goodson, 2017). Complexities surface because of medical advances such as improvement in assisted fertility, the improved survival of children born with congenital heart disease and the growing number of women of child bearing age with acquired heart disease (Cauldwell, Patel, Steer, \& Gatzoulis, 2016); as well as the steady increase in non-communicable diseases such as obesity (Nagle et al., 2011) and diabetes (Weston, 2014). This is reflected in New Zealand maternity statistics from 2017 as reported by the Ministry of Health (2019b). They report that the elective caesarean section rates have increased consistently since 2008 and there's been a resulting decrease in the number of normal vaginal births. Fifty percent of women in labour and birth had at least one obstetric intervention including epidural analgesia, or augmentation of labour. Twenty-six percent of women had an induction of labour. 
The report noted that $26.5 \%$ of the women giving birth in 2017 were obese. Women who are obese have an increase in adverse outcomes (Nagle et al., 2011) and women who have a BMI of greater than 40 meet the criteria for a clinical transfer of care to the obstetric team (Ministry of Health, 2012). Obesity has a strong association with gestational diabetes; the higher the BMI the higher the association (Daly et al., 2017). Women in the most deprived neighbourhoods had a higher proportion of obesity than women in the least deprived neighbourhoods. Thirteen percent of women giving birth reported they were smoking at first registration. Smoking is associated with smaller babies and premature births.

Women with complex pregnancies commonly have co-morbidities (Sandall, Coxon, Mackintosh, Rayment-Jones \& Page, 2016). A variety of different health and social services are required for some women, when there is medical, social and obstetric complexity. A number of different carers become involved and this can result in discontinuity of midwifery care, especially if the woman is unable to retain her own midwife. Some District Health Boards (DHB) in New Zealand are developing speciality services such as a high-risk diabetic team, consisting of obstetricians and midwives. This means continuity of care for individual episodes but not for the entire maternity experience (Daly et al., 2017).

Continuity of care helps people negotiate their maternity journey, but it should continue throughout the whole pregnancy to avoid poor transitions and handovers between caregivers. There is however a paucity of evidence about the outcomes of continued continuity of care in maternal complexity. It may be useful to consider what women with complexities want and value regarding the care they receive from midwives and if this is different from the care that the midwifery model delivers for low risk women.

\section{The aim and objectives}

The aim of this research is to provide a description of how women with complexities experience continuity of midwifery care across the maternity episode. While there is evidence of the success for low risk women receiving continuity of care, there is a gap in the literature about high risk women. Women with complexities with also comorbidities are more likely to experience 
fragmented care which contributes to problems (Sandall, et al., 2016). The aim of my thesis is to listen and then plan the provision of midwifery care which the woman considers optimal for her. It may not be continuity of care across the maternity episode but rather episodes of care. To achieve this aim I chose to use a qualitative descriptive approach as noted by Sandelowski (2000) which would allow me to achieve a comprehensive description of the women's experiences. I interviewed three women with different complexities. The first woman had an existing medical condition requiring transfer of clinical care to the obstetric team. The second woman had social complexities, developed clinical complexity during her pregnancy, and was transferred to the obstetric team during labour. The third woman developed complexity during pregnancy necessitating a transfer of clinical responsibility.

My intention is to use the experience of these women who had continued midwifery care in complexity to begin a conversation on optimal midwifery care for individual women experiencing complexity.

\section{My story}

I have a strong background in providing continuity of care across the risk spectrum. My own experience of providing continuity of care and the feedback the women I worked with provided to me over the years, demonstrated to me the importance they placed in having a known midwife providing care throughout pregnancy. This provoked my interest in continuity of midwifery care across the risk spectrum and hence this research. Working in the continuity model changed my perception and practice of midwifery. I came to New Zealand from South Africa specifically to work in the midwifery continuity of care model.

My initial experience of the New Zealand model of care was that most community midwives stayed with their women throughout the maternity episode. However, there was a gap in the continuity of care for women with existing medical and obstetric conditions. If a woman developed an obstetric complication during labour, her Lead Maternity Carer (LMC) midwife continued care. If the woman had an existing medical condition or became complex in her 
early pregnancy, she was transferred to the secondary obstetric service which resulted in her inability to have continuity of midwifery care.

I carry a small caseload and I know that the women with complexity in my care are more time consuming, have more antenatal visits, require agility in keeping track of other specialist input but the work is rewarding and has better outcomes for the women.

It would seem today that community midwives have changed their practice. It is my impression that previously midwives stayed with their women despite evolving degrees of complexity. Anecdotally I have observed in practice over the last three or four years that community midwives are increasingly handing over the care of the women either in pregnancy or in labour to the secondary service. Complexity is increasing (Ministry of Health, 2019b) and more midwives feel that they do not have the experience to look after these women or the time needed to provide comprehensive care. They also feel poorly remunerated for the extra time that is needed. So, from my perspective, the women who probably need the primary relationship of trust the most receive fragmented care.

Rayment-Jones, Murrels and Sandell (2015) suggest that women who experience continued continuity in complexity will value different aspects depending on their individual complexity. Skinner and Dahlen's (2015) state that continuity of midwifery care with healthy collaborative practice can bring extraordinary results. These suggestions along with my own belief in continuity have motivated my undertaking this research topic.

\section{Thesis outline}

This chapter has described midwifery continuity of care and the context, aims and significance of the research. Complexity is increasing. The challenge for maternity workers is to cope with this and keep the women safe as they move across departmental boundaries and experiences different levels and models of care.

Chapter 2 describes and critically assesses the published literature on continuity of care. This includes different models of midwifery care in countries 
around the world. There is an emphasis on the relational aspect of midwifery care and how the model of care influences this relationship.

Chapter 3 outlines the study design and describes the chosen methodology. This includes the method of data collection, the ethical issues and a reflection on the trustworthiness of the research process.

Chapter 4 the findings are presented using a descriptive and thematic analysis of all the transcribed data.

Chapter 5 concludes the thesis. I discuss the findings and key messages and how they sit within previously published work. 


\section{Chapter 2: Literature Review}

This research is interested in how women who have complexity in childbirth experience midwifery care when they have their own midwife who stays with them right through the birthing process. As the central issue of this research is continuity of midwifery care in complexity, the literature examined for this study covers this. The question is deceptively complicated on a number of levels. Midwifery by its definition is concerned with the normality of birth and the experience of healthy women. Midwifery models of care have been developed with this premise in mind and midwifery led continuity of care models have traditionally sat in the primary sector. The focus has been the provision of care in the antenatal, intrapartum and postnatal periods to women of low obstetric and medical risk (Sandall et al., 2016) I have searched the literature for any (Dove \& Muir-Cochrane, 2014; Homer et al., 2017; Skinner \& Maude, 2015) evidence that continuous midwifery care in complex scenarios might be beneficial for women in birth outcome and/or in birth experience.

In New Zealand, continuity of midwifery care means "one midwife (and her backup colleague) providing midwifery care throughout the entire childbirth experience" (Pairman \& McAra- Couper, 2015, p.398). Complex pregnancy is determined by the presence of one or more medical, obstetric, psychological or social complications (Donnellan-Fernandez et al., 2018) and shifts the midwifery model into a collaborative structure. I sought literature on what kind of midwifery continuity of care is available internationally and what other current midwifery models are offered to these women when they develop complexity and are cared for by the multi-disciplinary team. Can the continuity of a midwifery led model of care support these women and is this something that women would choose for themselves? There are several concepts which need to be explained for a clear understanding of why I selected my particular research literature and how it has informed this study.

I have divided the literature into six sections. Each section covers a specific aspect of complexity and continuity of midwifery care, and how the findings have guided the process of this research. The first aspect summarises the concept of continuity of care. The second is a collation of relevant literature of what is known about different midwifery models and how continuity of care is 
structured within them to include or exclude women who have complexity in their pregnancies. The third section covers a broad examination of the outcomes of key global studies on midwifery led continuity of care with special focus on women described as low risk. The continuity of care for low risk women starts the discussion of why continuity of care in complexity may be an important area to research. The fourth section examines recent studies concerned with the relationship between the woman and the midwife during continuity of care. It was anticipated that the quality of any ongoing relationship was likely to be an important factor in women's satisfaction with continuity of care and perhaps in negotiating complexities or risk factors in childbirth or at the primary/secondary care interface (Dove \& Muir-Cochrane, 2014; Homer et al., 2017; Skinner \& Maude, 2015). The fifth section examines women at social risk, also known as 'vulnerable', these women have been found to have more negative birth experiences and outcomes (Beake, Acosta, Cooke \& McCourt, 2013; Homer, Leap, Edwards \& Sandal, 2017; Rayment-Jones, Murrells \& Sandal, 2015). Lastly, although I am focussing on continuity of care for women with complexity, I thought it was important to look what the literature might say about complexity and women's experience of discontinuity of care when their risk status changed.

I began my literature review by searching in CINAHL and PUBMED data bases. I used the terms midwifery, continuity of care AND risk - this yielded 91 articles. I then changed risk to high risk women, midwives and continuity of care. This yielded 6 results. Changing high risk to complexity and continuity of care yielded no results. I then searched continuity of health care - 844 results; reduced that to continuity of care and midwifery which yielded 199 articles. I changed the term to continuity of carer. I eventually chose a core group of studies as they had a similar definition of continuity of care that I am using in this study i.e. care across the antenatal, intrapartum and postnatal episode. I also followed up on related articles in the references used in these articles.

\section{Continuity of care}

As noted in the introduction, Freeman, et al. (2007) stated that continuity of care as a concept had a lack of clarity. They have grouped together certain 
characteristics that are included in the understanding of continuity of care. Freeman et al. have included the definition of Haggerty et al. (2003), but have expanded it to include flexible continuity and cross-boundary continuity. Most importantly they emphasize that it is the individual who experiences the continuity and they may have different views of it. Continuity of care belongs in the primary health sector and is women/client orientated. Prior to application within the maternity services, it was introduced to manage chronic illness in the community (Brand \& Pollock, 2018). As a community healthcare concept, continuity of care is a key component of midwifery models, which likewise sits within primary health care, recognising birth as normal life event (Guilliland, \& Tracy, 2015). Continuity of care in this context means one midwife and/or her backup providing midwifery care throughout the maternity episode (Pairman \& McAra- Couper, 2015). Jenkins et al. (2015) continue this support of continuity of care, claiming that it is particularly appropriate for maternity services, as pregnancy is a finite period but long enough for a relationship and trust to develop between caregiver and woman. Consequently, continuity of care is now a desired component of a midwifery service in many parts of the world. There are many variants of continuity of care in midwifery models; which one is most useful is a matter to research.

Wickham (2015) and Sandall et al. (2016) concur that there is wide variation in the definition of how midwives and women understand continuity of care and how health systems structure and fund it. It is a common theme that the variation of continuity of care makes it difficult to claim which model of care is responsible for the better outcomes.

\section{Types of midwifery continuity models}

There are different models of midwifery continuity of care. In this section I will examine these models, including how each interprets and delivers continuity. This is important for my research as it will illustrate how continuity of care is provided to women along the risk continuum. I have chosen to examine models of midwifery care in four countries, as together they illustrate different models and the degree to which continuity of care is provided to women across the risk categories. 


\section{Australia}

The funding of the health care service in Australia is complex as there are both private and state-based models of funding. This impacts on how maternity care is structured. The maternity sector in Australia called for a review of maternity services in 2008 and the findings were released in 2009. One of the key findings was that women were dissatisfied with the current system in spite of it being one of the safest in the world (Guilliland \& Tracy, 2015). They argued that the reforms for maternity were disappointing in the state sector where obstetric fragmented care was offered. However Wilkes, Gamble, Adam, \& Creedy, (2015) noted that the introduction of the private midwifery workforce which had access to hospitals to be with their women enabled women to choose continuity of carer. These midwives also offered continuity across the spectrum of complexity. This form of care was seen as important for high risk women who may be declined midwifery led care in the public sector (Davison, Hauck, Bayes, Kuliukas, \& Wood, 2015). Homer (2006) challenged the Australian midwives as to whether they were providing the level of continuity that women wanted in their midwifery models of care. She claimed that the movement towards continuity of care in Australia had been limited despite the evidence that supports this model of care. She also claimed that there were few case loading midwives and teams of midwifery despite the policy directives of the Department of Health to implement midwifery continuity of care models. The barriers were numerous: workforce issues, other professional groups and difficulty perceived by managers in implementing new ways of practice. The introduction of a public funded option for home births was strongly opposed by the Australian medical profession and has not flourished since then (Guilliland \& Tracy, 2019). The total number of women receiving continuity of care is still small. Despite the positive findings of two randomised controlled trials actually undertaken in Australia (McLachlan et al., 2012; Tracy et al., 2011) the current Australian model of care is still dominantly a fragmented, medical model (Thorogood, 2015).

\section{The Netherlands}

In the Netherlands, maternity care is organised in a primary, secondary and tertiary care model (Zondag, Cadee, de Gues, 2017). Perdok et al. (2014) note 
that in the Dutch maternity system low risk women receive continuity of midwifery care from primary midwives. Primary midwives have a scope of practice that covers low risk women only. Women who have an increased obstetrical risk must give birth in a hospital attended by secondary or tertiary care professionals. Either a clinical midwife, a general doctor or an obstetrician in training take a lead in the care. An obstetrician is called if complications arise. Thus, when a woman develops increased complexity, care is handed over to the hospital based clinical midwife and obstetrician. There is no continuity of care from then onwards. The rate of referrals of women from primary midwifery care to the secondary service has increased significantly over the last decade, and current research is addressing whether the model of care is still sufficient for the changing times (Perdok et al, 2014). Perdok et al. note that the Netherland primary midwives are arguing the case for women with moderate risk factors to retain continuity of care, since they may still birth vaginally. This perspective is useful for my study as it provides a snapshot about the women developing complexity whose care is handed over during labour. The model of care in the Netherlands is designed for continuity of care in low risk women only.

\section{United Kingdom}

Better Births is the named report from the UK's maternity review of their National Health System (NHS) (National Health System, 2017). The background to this report was a review of the current system and whether their vision that all women should have access to continuity of carer had been achieved. Their evidence was that there are better clinical outcomes and women have a more positive birth experience. The report challenged the local maternity systems to roll this out to all women by 2020/1. Sandall (2014) notes that continuity of care has been "at the heart of maternity policy in England since 1993" (p.3). Despite the evidence it has been difficult to roll out.

There are three main models of midwifery care in the UK which provide continuity of care - team and case loading models of care. In the team continuity model, a number of midwives working together provide care across the antenatal, intrapartum and postnatal episodes. This team approach to continuity of care, can consist of a team of 6-8 midwives who can all provide 
back up to the named midwife, in the event that she is unable to be with the woman in labour. In case loading midwifery, each midwife books a certain number of women for midwifery care and arranges her life around this. In this model the woman is most likely know the midwife who cares for her in labour. The second model has less of a component of continuity than the first model of care. The same midwife provides care across the antenatal and postnatal spectrum only. The core midwifery team provide care during the intrapartum period. Consideration may be given to teams of midwives to provide continuity of care for particular cohorts of women as where there is medical or social complexity. National Maternity Perinatal Audit Project team (2017) states that there is little provision of continuity of carer irrespective of how the midwifery model of care is organized. The need for continuity of carer is among the most prominent of recommendations from national maternity reviews. Only $3 \%$ of Health Trusts reported that their midwives carried a caseload (National Health System, 2017).

A third midwifery care framework incorporating consideration of continuity of care in the UK, involves continuity of carer during the intrapartum episode only. When a woman labours a previously unknown midwife will be assigned to her, and provide care for her throughout her labour and birth.

The NHS has challenges to embed full continuity of care despite the evidence that it improves certain measurable outcomes.(National Health System, 2017). This report includes a plan to have a hospital-based continuity of team who work collaboratively with the obstetric team for high risk women.

\section{New Zealand}

New Zealand had achieved complete integration of continuity of midwifery care across all levels under its partnership model of midwifery (Guilliland \& Pairman, 2019). The model of midwifery in New Zealand is based on continuity of care, which is protective of the two theoretical frameworks underpinning midwifery; namely partnership and cultural competency. This model was strategically developed so that the relationship between a woman and midwife had time to grow, to develop trust and direct care (Kennedy et al., 2004; Tracy et al., 2013). 
The legislative framework that outlines the model of care provides that each woman chooses a Lead Maternity carer (LMC) to provide care which allows for continuity of carer throughout the maternity care episode (Guilliland \& Tracey, 2015). The model is one-to-one care from a Lead Maternity Carer who can be an obstetrician, a general practitioner who has a diploma in obstetrics or a midwife, with a named back up and is set up to work collaboratively. The Ministry of Health (2019c) reports 92.3\% of women giving birth in 2017 received primary maternity care from an LMC. The proportion of women registered with a midwife LMC increased significantly over the same period, from $89.7 \%$ to 94\% (Ministry of Health, 2019c).

This is the model that provides the greatest chance of continuity of individual carer. Literature supports that women integrated in this model of care are more likely to receive continuity from the same caregiver across the antenatal, intrapartum and postnatal episodes as long as the women is low risk (Beake, Acosta, Cooke \& McCourt, 2013; Homer, Leap, Edwards \& Sandall, 2017; Rayment-Jones, Murrells \& Sandall, 2015; Tracy et al., 2013). The New Zealand model allows for continuing midwifery care for women with existing medical conditions or developing complexities requiring referral to the obstetric team (Ministry of Health, 2012). When a woman's care becomes complicated the midwife is obliged to offer a transfer of clinical responsibility to the appropriate care provider; usually the obstetric team. The midwifery care is negotiated between the woman, the primary midwife and the obstetrician. The midwife can retain care and provide continuity of care in complexity but she may choose not to do so. The Ministry of Health (2011) developed a set of standards to provide a structure for equitable safe and high-quality maternity services This includes measuring the numbers of women with additional health and social needs who receive continuity of midwifery care to increase this number overtime. This strategy hopefully will increase continuity of care to women experiencing complexity.

Midwives do offer continuity of care across the abnormal/normal divide adhering to a strong philosophy of women centred care. Davis and Walker (2011) argue that women in New Zealand experience continued continuity of care regardless of the complexity as midwives construct continuity as the core 
of care as opposed to normal birth. In exploring midwives' patterns of providing care when a woman required additional care Skinner and Foureur (2010) found that $74 \%$ of women who had a transfer of clinical responsibility continued care with their midwife, in collaboration with the obstetrician. There is a history of continued care in this model but there is the potential for handover of midwifery care with increasing complexity; the consequence is discontinuity of midwifery care. Skinner and Fouruer conclude that their research may form the basis of 'how midwifery-led care may meet the needs of women experiencing complexity in childbearing' (p.35). Skinner and Maude (2016) commented on the concept of risk in midwifery practice, using a critical realist lens. They found that the midwives stayed to provide care. The midwives believed that the women with complexity were in more need of continuity than low risk women. They continued to provide women with complexity with continuity during pregnancy and/or birth. This seems a logical conclusion. However this research was undertaken in 2005 and much may have changed in the last fifteen years.

As discussed, often with increasing complexity comes increasing fragmentation of maternity care (de Jonge, Stuijt, Eijke, \& Westerman, 2014) when the wider multidisciplinary team has input into the care of the woman. Whereas, the risk of a woman with a low risk pregnancy requiring services additional to midwifery, is low.

Engagement with a community midwife in the first trimester enables opportunities for screening, education and referral, and begins the primary maternity continuity of care relationship between a woman and her midwife. This relationship may provide the opportunity to maintain as much normality as possible within the context of complexity. New Zealand is the most appropriate context for this study as it is here that women with complexity can have continuity of midwifery care.

\section{Outcomes of midwifery led continuity models of care}

There is extensive research which has explored the outcomes and added to the body of knowledge of how we might improve care. A substantial number of these studies relate to low risk women and the outcomes in relation to continuity of midwifery care. I sought randomised controlled studies using midwifery-led continuity of care models as the intervention. Most studies 
measured outcomes for low risk and mixed risk women. Complexity and continuity have not been a focus of the research.

Midwifery-led continuity models of care differ from standard models of care in terms of the lead professional role. In the midwifery-led continuity models the midwife works in partnership with the woman, is responsible for assessing and together with the woman plans her care. Other models of care have a different philosophy where care is shared between different health professionals and the women may meet her care provider for the first time when in labour. The intervention of midwifery-led care on outcomes for the mother and baby in randomised controlled studies began to be examined in the 1980's and Sandall et al. (2016) collated a systematic review of midwife-led continuity models versus other models of care for childbearing women. They reported that women who received continuity of care were less likely to experience regional analgesia, instrumental vaginal birth, preterm birth which is birth before 37 weeks, and less foetal loss before and after 24 weeks. This review summarised 17 trials with 17674 women from Australia, Canada, Ireland and the UK. All women were of low or mixed risk. They defined low risk women as having uncomplicated pregnancies. The emphasis of care in this study is on the ability of women to experience birth with no intervention. Women of mixed risk were women who were healthy and had an uncomplicated pregnancy but required some visits with a general practitioner or obstetrician as part of the model of care. Women with significant disease and substance abuse were not included in the trials. This review concluded that evidence was insufficient to determine whether or not continuity of care was of clinical benefit to women who had substantial medical or obstetric complications.

As well as better clinical outcomes, those in the low risk group also demonstrated higher rates of maternal satisfaction (Sandall et al, 2016). However, the concept of satisfaction was not consistently measured across the studies and was not necessarily about continuity of care. The women were most satisfied with their control in labour, and how they were able to cope physically and emotionally. None of the literature indicates any evidence of poorer clinical outcomes for women, or babies, under a continuity of midwifery care model. What this systematic review is unable to answer is to what extent 
the "observed benefits can be attributed directly to model of midwifery care, philosophy of midwifery or quality and degree of relationship between the care provider and the woman" (p.24).

What is less clear is whether continuity of care makes a difference for mothers who develop complexities during their pregnancies (Sandall et al., 2015; Tracy et al., 2013). Tracy et al. addressed this in their randomised controlled trial (RCT) which aimed to assess the clinical cost and outcomes of caseload midwifery care for women irrespective of risk factors. Eight hundred and seventy-one women were randomly assigned to caseload midwifery care and eight hundred and seventy-seven women were randomly assigned to "standard" care. The standard care in this RCT is a model of fragmented care meaning the woman will have different midwives and obstetricians to assess and plan her care. The main primary outcome that they wanted measured was caesarean section. Other outcomes were assisted vaginal birth, normal vaginal birth and epidural analgesia. The outcome for this intervention was that women who had caseload midwifery care were less likely to have an elective caesarean section. Other statistics did not differ significantly for primary outcomes.

In the New Zealand context it would be useful to know if the maternal satisfaction and trust that contributes to the good outcomes for low risk women can be replicated for high risk women. Forster et al. (2016) and McLachlan et al. (2016), looking at secondary outcomes of women's experience of childbirth from their randomised controlled study concluded that the women who received caseload midwifery had a more positive experience. In qualitative studies women, have described the importance of the relational aspect of continuity of care, especially the development of trust studies (Perriman, Davis, \& Ferguson, 2018). This aspect has not been explored satisfactorily by the authors whose studies were included in this key systematic review. It may be the relational aspect that allows lower intervention and observed benefits. If women are to be offered, or they indicate preference for, the option of continued continuity of midwifery care when their pregnancies become complicated, it is important to identify that the provision of this option is informed by robust evidence and made available to them. 


\section{Women with Social Complexity}

Midwifery is said to sit in the primary health sector which is also the place concerned with examining the social determinants of health (Eddy, 2019). Social complexity is an area that midwives can address both politically and in health outcomes. Disparities are being addressed in the western world. Evidence suggests that women with complex social needs benefit disproportionately in terms of outcomes from continuity of midwifery care (Beake et al., 2013; Homer et al., 2017; Priday, \& McAra-Couper, 2016; Rayment-Jones et al., 2015). These authors examined the impact of continuity of carer compared to other midwifery models of care. Rayment-Jones et al., (2015) noted the relationship between social complexity and increased rates of maternal and foetal morbidity. It therefore made sense to study women with social complexity across the risk spectrum. Also, from my personal experience it is these women who are less likely to have continuity, either because they are inclined to book late, or midwives are less keen to book because of the added time and resources these women may require.

Homer et al. (2017) undertook a retrospective analysis of the outcomes of women who accessed the UK Albany Midwifery Practice from 1997-2009. The Albany practice was started by six midwives who provided case-loading continuity of midwifery carer model to the women living in a known economically deprived district in southeast of London. The data was analysed after these women had accessed care from the Albany midwives. These midwives achieved a $98 \%$ rate of attending to the women in labour and their clinical outcomes demonstrated less intervention, more spontaneous vaginal births and home births. Homer et al. (2017) further found that relational continuity of carer in a case load model of midwifery care is able through trusting relationships to break down barriers to accessing care. However, the study did not state whether the nominated midwife stayed with the women in labour as complexity evolved, or whether she handed over care to a hospital midwife.

Better clinical outcomes with lower intervention for women who received continuity of midwifery care was supported by Rayment-Jones, Murrells and Sandal (2015) in their comparative study on the outcomes of vulnerable 
pregnant women. The comparison groups were a caseload continuity of care model and a group receiving standard care. Continuity of care assisted women not only to have better clinical outcomes but women in this group were more likely to be referred to services providing social support for domestic violence, depression, language translation services. This support all contributed to improved health and parenting skills.

Cultural sensitivity and safety were positive aspects for women through the developing relationship with the midwife. Beake, Acosta, Cooke and McCourt (2013), claimed this in their evaluation of outcomes of case load midwifery in a socially deprived and ethnically diverse inner-city area. Continuity of care happened for all women regardless of complexity. The women felt that the communication with the midwife led to an understanding of their cultural needs and through this a trusting relationship developed. Cultural safety is one of the frameworks that supports continuity of care (Eddy, \& Campbell, 2019). It's interesting that midwives who provide continuity of care for socially disadvantaged women provide care across the clinical risk spectrum and not only for low risk women.

\section{Importance of relationship within a continuity of care framework} Regardless of the context of maternity care, developing trusting relationships between the midwife and the woman is a central theme in many midwifery texts. The continuity of carer model is based on developing a high-quality relationship. The benefits of continuity of care could be due to the degree of the quality of this relationship which is the catalyst for evolving trust throughout the maternity episode (Lewis, Jones, \& Hunter, 2017). They describe the development of trust as "building blocks" (p.11). Both women and midwives speak of trust as the core of the relationship. For women, trust is directly related to their sense of safety, of feeling in control and of enhancing their confidence. It is also important that trust is reciprocal (Davison et al., 2015; Dove \& MuirCochrane, 2014; C. S. Homer et al., 2017; Kuliukas, Duggan, Lewis, \& Hauck, 2016; Lewis et al., 2017; Perriman et al., 2018; Rayment-Jones et al., 2015). For midwives, this reciprocal trusting relationship was essential for uncovering risk factors which may impact the labour. This includes social risk (Dove \& MuirCochrane, 2014; Homer et al., 2017; Rayment-Jones et al., 2015). Midwives 
were then able to provide information and support for women developing clinical complexities. This included referring them to the appropriate care provider at the primary/secondary care interface (Skinner \& Maude, 2015) and negotiating alternative care planning with the woman (Davis \& Walker, 2011). Skinner and Maude (2015) note that in increasing complexity it was even more important for "continuing the relationship in which trust had been formed" (p.37). They can trust that the midwife will act in their best interests when they are in too much pain to think clearly and when they are vulnerable in labour (Lewis et al., 2017).

Excluding high risk women from the option of engaging in a continuity model of midwifery care may provoke women to choose options outside of mainstream models of care. Davison, Hauck, Bayes, Kuliukas and Wood (2015) interviewed women who deliberately sought the service of a private midwife to provide the relational aspect of continuity of care they considered optimal for their childbirth process. The care that had been offered to these high-risk women was characterised by fragmented obstetric care which increased their sense of anxiety and fear. The women declined to engage in this service as it felt unsafe for them. The feeling of safety was crucial for them to the extent that they considered self-birth the preferred option. However, they engaged the service of private midwives who could provide the feelings of safety and control within a trusting relationship which the woman formed with the midwife. This study indicated that the value the high-risk women placed on their feeling of safety and control was an outcome of their trusting relationship.

In contrast to this, there are women who did not perceive that continuity of midwifery care and the relationship had any value for them. Is this also about trust? I am wondering if the addition of the medical perspective encourages women to put their trust in other things and so continuity is not so high up on what they perceive to be important. But the need to trust is still there. It is just placed elsewhere. Some women experiencing high risk pregnancies declined continuity of midwifery care as they were anxious and felt they needed care from the obstetric team only (Dove \& Muir-Cochrane, 2014). Boyle, Thomas and Brooks (2016) support this finding. Some women, with varying complexities identified the importance of time spent in antenatal appointments discussing 
risk rather than having continuity of care. Continuity of midwifery care does not always ensure a trusting relationship according to the aforementioned authors. They also found that fifty percent of the women who had received continuity of midwifery care did not think that they had formed a relationship with the midwife. The women thought it was due to a lack of emotional support which was not helped by the time constraints placed on antenatal appointments. The women also identified that the relationship development was impacted by the involvement of multiple midwives in their care, and assumptions by their caregivers about the decisions they would make. This is interesting and relevant to our current situation. It highlights how constraints forced upon us by such things as workforce retention and burnout can impact on attitudes towards continuity and relationship.

These findings highlight the challenges of introducing continuity of midwifery care frameworks into an existing, predominantly medicalized environment which is not necessarily woman centred. For some women, continuity of care did not matter when they developed complexity in their pregnancy or labour. This is interesting, as again it differs from a previous finding that complex women did value continuity.

\section{High risk women's experience of discontinuity of care}

Because I am interested in continuity of care in complexity or when higher risk is identified, I felt it necessary to examine more closely the literature on high risk women's experience of discontinuity of midwifery care, especially in light of the above findings that some women do not want or value continuity. This issue is addressed in the growing evidence of the impact of discontinuity of midwifery care occurring at the transition from primary to secondary care services (De Jonge et al., 2014; Jenkins et al., 2015; Kuliukas et al., 2016). The Sandall et al. (2016) systematic review was primarily around low and mixed risk women. High risk women were not included. If the evidence is only concerned with low or mixed risk women there will be women who experience discontinuity of care when they become defined as high risk.

There is little evidence about the clinical outcomes for women with significant complexities who manage to have continuity of midwifery care. There is however evidence of these women's experience of discontinuity of midwifery 
care. de Jonge, Stuijt, Eijke and Westerman (2014) in their Dutch study, interviewed twenty-seven women about their experience of transfer of midwifery care. The women were low risk prior to the onset of labour and then developed complexity or wanted an epidural. The women had been 'handed over' to the hospital-based clinical midwife. The women commented that the continuity of care with the known midwife contributed to their feeling of safety during labour. When handover of care was indicated, the women preferred the primary midwife to hand over the care in person and stay with them until they were settled. Together with their loss of feeling safe the women reported that their information about their preferences can get lost during the handover of care. This increased their feelings of anxiety and fear.

Building on those findings and noting the increase of referrals from the primary midwives to the obstetric team during labour, Perdock et al., (2014) designed a study to address how the primary care midwives could involve themselves more in providing continuity of care to the women when they have developed moderate risk factors. Only one risk factor condition was agreed on amongst the multi-professional team. The consensus was that integrated care was desirable but the clinical midwives who provided care in the hospital were anxious not to lose their status on the labour ward. It would have been beneficial to speak to the women concerned given the increase of referrals and handover of care required with the increase of women being handed over. The authors have called for further research in this area.

Similar findings were drawn from a study in the UK examining factors which women described as mitigating a negative birth experience during handover of midwifery care. Not only did the women change their place of birth but there also was a transfer of midwifery care. This study aimed to address the experience of women when a transfer of care from the primary midwife to the secondary care midwife occurred (Kuliukas et al., 2016). The authors noted that the midwife supporting the woman had an important role in supporting her to adapt to her new circumstance. As in the Dutch study, the women also commented that they would have preferred the primary midwife to stay with them until they were comfortable with the handover of care. 


\section{Summary}

The following conclusions are drawn from the literature review. New Zealand is the appropriate country to research continuity of care where existing or developing complexity in pregnancy arises. The model of midwifery care here is structured to accommodate continuity of care to all women. Continuity has clinical benefits for low risk or mixed risk women but has not been demonstrated for high risk women. Discontinuity of midwifery care from the primary to the secondary setting in the event of a woman developing complexity has a negative impact on woman's experience of labour especially around feelings of safety and loss of informational continuity. It has demonstrated lower obstetric interventions with good outcomes in vulnerable communities. The relationship is important to woman and midwives.

Women may not experience a relationship in continuity of care or even desire continuity of care when there is increasing complexity or anxiety relating to increasing risk. These findings are important for my research question as it begs an exploration of a topic where there is not much available information. Therefore, it would be useful to explore how women talk about their experience of continued continuity of care with their own midwife using a qualitative method of enquiry. 


\section{Chapter 3: Methodology and Design}

\section{Introduction}

This chapter explains the choice of methodology and method used in this research. It covers qualitative research, qualitative description, participant recruitment, data collection and analysis. The methodology chosen is qualitative description. Qualitative description was chosen to guide the design and analysis of the study.

This chapter is about how I went about answering my research question. The first three sections justify my approach; the rational for the approach; and then the overall fit of descriptive qualitative methodology. The next three sections are concerned with the research design, recruitment of participants, data collection and analysis. I end with discussion on the research in light of the Treaty of Waitangi, the ethical considerations and a reflection on the rigour of the study.

\section{Choice of research approach}

The literature review, drawn from a variety of international and national studies on continuity of care, together with practice considerations, have informed my research methodology. Findings that continuity of care is beneficial to low risk or mixed risk women, but has excluded high risk women from the research, reveal a gap in the body of knowledge. Despite indicating that that loss of continuity of care can have a negative impact on woman's experience of labour, especially in feelings of safety and loss of informational continuity, there was nowhere that explored the benefits of continuing care 'for all women', including those with complexity. These findings are important for my research question as they indicate the usefulness of an exploration of a topic where there is minimal information in the literature. The findings describe the impact of discontinuity of care on women who have complexity and the disregard of women's choice. What is not known is what women value about continuity of care. The aim of this study is to explore just that; how do women experience continued midwifery care where social or clinical complexity has been identified? 
In general most midwifery models care are focused on low risk women and the evidence indicates that continuity of midwifery care is protective of vaginal birth for this group of women. When things become complex, the quality of relational continuity of care is pivotal, especially in negotiating care at the primary/secondary care interface (Dove \& Muir-Cochrane, 2014; Homer, et al., 2017; Skinner \& Maude, 2016). This is claimed by midwives in the literature, not the women themselves. Given the aims of this research, providing description of the experiences of women who do have access to continuity of midwifery care in clinical complexity, has the potential to offer a "rich, .... detailed description.....in which the complexity and contradictions of participants' stories of their lives are included" (Braun \& Clarke, 2014 p.24). My study is a start in understanding what is important to women in this context and may inform improved care.

The term methodology refers to the research approach (Cluett, \& Bluff, 2006) or the framework. This framework indicates the method of data collection and the process of data analysis (Braun \& Clarke, 2006). According to Braun and Clarke (2006) and Liamputtong, (2014) qualitative research is about words and meanings people attribute to their own experience of something. It is a useful way of exploring areas where there has not been much information found or researched (Liamputtong, 2014). This resonates with the question I have posed for this research. There is a paucity of literature on what women think or value about their relationship with a midwife in a context where continuity of midwifery care in complexity is possible. In some midwifery models women do not get a choice in their care being handed over to another party resulting in discontinuity of care. I am curious about how women talk about their experience of continued midwifery care, especially when they are free to be frank. I am also keen to look for perspectives that I may not have thought of (Braun \& Clarke, 2006). The best place for me to start is by talking to women who have experienced continuity of midwifery care in complexity. Braun and Clarke (2006) talk about people making their own sense of the 'messiness' of real life. This approach enables people to make sense of their experience. There is a continuum of different methodologies under the umbrella of qualitative research and each one gathers data which hopefully will provide answers to the asked question. 
A quantitative approach on the other hand is concerned with objective measurable reality. An example of a quantitative question which could also give us good information is: how many women with complexity are being handed over from their primary midwife to hospital staff for care? This would inform us on how many women have discontinuity of care but does not tell us whether this matters to the women. What I want to know is about the women's experiences and this is why I have chosen a qualitative research.

\section{Qualitative description}

I have chosen a qualitative description approach as described by Sandelowski (2000). Qualitative description has as its goal "a comprehensive summary of events in the everyday terms of those events" (Sandelowski, 2000, p.336). In keeping with capturing the descriptive aspect of the event the researcher avoids transforming the data according to an underlying theoretical approach. The difference in this methodology to other qualitative approaches is that the event can be recognised by other researchers. The experience is described by the person and is not reinterpreted. The experience is familiar to other people who have experienced the event and agreed on by other researchers. The data is captured in the setting that it occurs which is described by Sandelowski (2000) as a natural setting. The meaning of the analysis lies close to the data. It is not transformed by a theoretical lens. In a systematic review of qualitative descriptive studies Kim, Sefeik and Bradway (2017) state that the word 'explore' occurs a number of times in this methodology and thus it is suited to exploratory topics. Qualitative description can be seen as the starting point for further research.

I want to ensure consistency in the purpose of the study and the method of data analysis. As there is not much known about the topic, I want to stay as close to the data as possible (Sandelowski, 2000). The women were encouraged to describe their experience in everyday language; what it was like for them. This starting point fits with the qualitative descriptive methodology described by Sandelowski (2000).

Qualitative description offers a comprehensive summary of the event through the participant's eyes. They will see parts of the event that a midwife might not see and because of this I wanted to keep to the actual words the participants 
use. While it can be useful to interpret in great depth, it is of value to take the meaning as the participant stated at face value.

The descriptive qualitative approach I take is exploratory in nature. As such it has the potential to offer a rich, description of 'how it is' for these women in reality. Their stories can be told in everyday accessible language (Sandelowski, 2010). I heard and recorded the interviewee's perspectives in their own words. This approach can also explore both commonalities and differences across a range of cases, an aspect particularly suited to the phenomenon of continuity of care.

Qualitative description draws from a naturalistic enquiry which simply means that 'the researcher studies something in its natural state and does not attempt to manipulate or interfere with the ordinary unfolding of events' (Colorafi \& Evans, 2016, p.18). It was important to understand the experience of complexity in its natural setting.

\section{Interview as chosen method}

The method of quality enquiry that I chose was in-depth interviews. This enabled the collection of rich in-depth data. According to Liamputtong (2014) a semi structured interview will provide a fair overview of how the interviewees have experienced the event.

\section{Recruitment}

For this study three women were recruited via the community-based midwives. The size and scope of this study precluded a large number of participants, as it is a small exploratory study. The women were selected from different categories of complexity in order to maximise the variation of the experiences. The women needed to have had continuity of midwifery care, that is, the same midwife caring for them in the planning, organization, and delivery of midwifery care throughout pregnancy, birth, and the postpartum period ( Sandall, et al., 2016). For this study, complexity was confirmed when a woman's pregnancy, birth or the postpartum period was complicated by a condition considered an indication for transfer of clinical responsibility to obstetric services, as per the Guidelines for Consultation with Obstetric and Related Medical Services (Referral Guidelines) (Ministry of Health, 2012). When transfer occurs, the 
obstetric service is responsible for the clinical decisions. The only exception was women who were experiencing social complexity. I had noted that these women were being handed over to the hospital services for care and thus I wanted to look at their experiences too.

The three categories of complexity I included were:

- A woman whose pregnancy was complicated by a pre-existing health condition. The condition would be considered an indication for transfer of clinical responsibility to obstetric services, as per the Guidelines for Consultation with Obstetric and Related Medical Services (Referral Guidelines) (Ministry of Health, 2012).

- A woman who experienced acute complexity necessitating a transfer of clinical responsibility to the obstetric team. These conditions are unexpected and are also described in the Referral Guidelines.

- A woman who has social complexity. I found it difficult to find a succinct definition for social complexity. It was not in the Referral Guidelines. I decided to use the description provided by the National Maternity Working Group who use the term 'vulnerable women' as opposed to social complexity (Ministry of Health, 2018.) The Working Group suggests that vulnerable women require care from a multidisciplinary group including continuity of care and health worker or community worker support services. They too found definition difficult but did agree on the risk factors that can contribute to vulnerability. These risks relate to the mother's situation, the home environment and factors relating to the pregnancy, birth and postnatal care. These factors are what I have used to define vulnerable woman. (Ministry for Women, 2018). Vulnerability should be viewed as a complex phenomenon as Briscoe, Lavender and McGowan (2016) argue rather than a singular concept.

To recruit participants, my initial intention was to provide an information session for midwives in the community at the interface meeting between the hospital midwives and the community midwives. This group meets once a month to have a conversation about the hospital/community interface. However, this was not necessary as I had informally discussed my study with my community 
colleagues either in the maternity unit or socially. They were very excited about the research and wanted to help. Rather quickly midwives recruited three appropriate women. The participants were provided with a letter of invitation and written information regarding the purpose and design of the study. I was hoping for a woman representing each category, but it did not turn out exactly like that. I learnt that indeed, complexity is not predictable.

Together with the nurse diabetic specialist I had organised a diabetic study day for the midwives in the area. A consumer was invited to attend to talk with the midwives about how she managed her diabetes on a daily basis to achieve optimal health. She gave an enlightening presentation and was honest about her journey. I approached the diabetic nurse specialist and asked to see if this woman might like to be one of my participants, and gave the nurse an information sheet to offer to her. The women did contact me and said she would be interested in participating.

I had also provided information to a group of community midwives that I knew seldom handed over the care of the women in their practice. This was the source of my second participant. The midwife gave the woman the information sheet (Appendix 2) and she texted me that she was interested. The third women was recruited by a new graduate community midwife who had provided care for this young woman. Not only did she fit the criteria for social complexity, but in the end she also had an emergency caesarean section. She texted me to say that she was happy to talk to me. From practice I knew that women with social complexity often have clinical complexity, but I did not factor this in when I was recruiting. This case sits easily within a purposeful sample as it demonstrated the relationship between social complexity and clinical outcomes for some women.

\section{The interviews}

The interviews were flexible and gave me the opportunity to respond to new information and to probe deeper. I had three very different women to talk with. The goal was to get the participants to talk about their experience using their own language and words. The interviews were semi-structured, utilising openended questions. My interview questions were a guide only, providing prompts 
where necessary or to lead discussions that might have gone astray back to the topic in hand. The guiding questions were:

- Tell me about your relationship with your midwife.

- Tell me about your experience of midwifery care.

- How did your midwife discuss the issues and the uncertainty that you were experiencing?

- Tell me about the information that your midwife provided to you.

- What were the best things about having a midwife you knew with you?

- What were the challenging things about having the same midwife?

- Did the midwife give you a choice of another midwife?

- How did you assess the competency of the midwife especially when things were not going too well?

- What made you anxious?

- Was there an indication from the midwife that she may be required to hand over your care and if so how did that make you feel?

- What role do you think your midwife filled for you?

- It may be necessary to offer further prompting to maintain focus on midwifery care but, primarily, the interview process was directed by the woman.

I rang each woman, had a conversation about the research and answered any questions that they had. I arranged a time and asked them where they would like to be interviewed. Two women chose their individual homes and the third woman chose her mother's home. Pseudonyms have been used throughout to identify the women.

The first woman I interviewed was Heather. Heather fitted the criteria as she had a pre-existing medical condition necessitating a clinical transfer of responsibility to the obstetric team. She has type 1 diabetes. She lived in a house that she and her husband were renovating. She welcomed me warmly and that set the tone for the interview. After the consent process (Appendix 3) was finished, we started the interview. I asked few questions as at the start Heather declared her keen interest in this research project. This was a comfortable interview; two hours flew past. 
Kate, the second interviewee, had moved towns since the birth and opted to be interviewed at her mother's house. She had her baby with her so we could start off the conversation chatting about how her baby was progressing. Kate had originally told me that she had no existing medical problems, but it turned out that she had had a congenital heart condition! This did not trouble her at all as it caused no problems and she had been discharged from all care. It was not a risk factor for her. Kate's baby had not grown well towards the end of her pregnancy and she had been referred to the obstetrician for a clinical transfer of care. Her community midwife continued care for them right through the process up to six weeks postnatally.

The third interview was with Felicity. She rented a small room in a house in a deprived area of the community. She, her partner and the baby all lived in that one room. There was no space for other furniture except the bed. The baby had a pepipod (a safe sleep container) as neither a bassinette nor cot could fit into the room. Felicity and I sat on her bed while I interviewed her. Her baby was sleeping in the pepipod on the bed. She wanted to talk to me as she was delighted with her midwifery care, although she claimed that talking wasn't her strong point. I needed to ask her lots more questions than the other two women as she was a little shy and did not volunteer information easily.

The interviews were audio recorded with consent from the participants.

\section{Data Analysis}

The interview transcripts were analysed using qualitative thematic analysis (Braun \& Clarke, 2014). This type of analysis is used often in a qualitative descriptive approach (Vaismoradi, Turunen, \& Bondas, 2013). Thematic analysis as an independent qualitative descriptive approach is mainly described as "a method for identifying, analysing and reporting patterns (themes) within data" (Braun \& Clarke, 2006, p. 79) and can be used to answer any research question as it is flexible (Braun \& Clarke, 2014). The authors claim that this is useful for topics which the researcher would like to explore using an inductive approach, meaning the themes are identified from the data itself as this is an exploratory topic (Vaismoradi et al., 2013). 
It has been suggested that thematic analysis, as a flexible and useful research tool, provides a rich and detailed, yet complex, account of the data (Braun \& Clarke, 2006). It can be used to develop a descriptive account of the data where the intention in qualitative descriptive methodology is to achieve a lessened level of interpretation which stays close to the words of the participants. Thematic analysis uses the data to support the low level of interpretation of the findings.

I transcribed the interviews myself and initially hand wrote the transcription. These were subsequently captured electronically. This was to start familiarizing myself with the data. I began to identify themes and patterns related to my research question which I actively looked for across all the data (Braun \& Clarke, 2014). Once I thought I had understood the women's stories quite well, I wrote a summary of what I thought the interview was about. In re reading the transcripts I made changes, adding to or deleting parts of my summaries. This simplified the coding task as I was making notes of what I thought were patterns. This initial summary I found was key in starting the analysis.

I already had a good idea of what was in the data. I identified and marked extracts of the data. I didn't decide what the data meant because it needed to be self-evident, as this is a descriptive approach. I highlighted the description of what the women felt and valued, using their own words, also acknowledging that there is always an interpretive aspect in understanding what another person is saying. These extracts of the data became the codes. After the first thorough checking for codes across the transcripts, I thought I had finished but soon realized that this is an iterative process.

I then allocated a colour to each woman and organized the codes which I thought were similar onto different coloured posters. I changed them around over time until I was satisfied that I had organised similar codes on different coloured posters and they had similar meanings. There were four themes with subthemes under each of them. These were

\section{The relationship was everything}

- Having mutual trust and respect

- Grateful for the care 
- Feeling close and comfortable

- A calm and composed midwife

\section{Knowing what was happening was important}

- Clarifying the midwifery role.

- Interpreting medical information

- Listening and teaching

- She had the big picture

\section{Power was managed and balanced}

- Being empowering and uplifting

- Advocating

- Shared decision making

\section{Extra care was needed}

- It was hard to find a midwife

- The midwife relieves fear and anxiety

- She was always there

\section{Treaty of Waitangi}

As the research was undertaken in New Zealand, the Treaty of Waitangi principles of partnership, participation and protection needed to be honoured in all areas of the research. Participants invited to take part in the interview were asked if there were any cultural preferences they would like addressed during the interview and with the information they disclosed. I did have a Māori advisor on hand should I have any Māori participants. In the end no participants in this study identified as Māori.

\section{Ethical consideration}

The inclusion of human participants in research requires that a formal ethics approval application is made either to Health and Disability Ethics committee (HDEC), or to the University Human Ethics Committee (HEC), depending on the size of the research. In the first instance, I applied to the University HEC who advised I make a formal application to Health and Disability Ethics committee (HDEC). HDEC, who, after consideration, returned their conclusion 
that my study did not meet their criteria for consideration and directed me back to the University Human Ethics Committee (HEC). Ethics approval was gained from the university ethics committee on the 30 ${ }^{\text {th }}$ November 2017 (Reference number 0000025306) for a three-year period. (See Appendix 1) I noted and acted on the four ethical principles in the work of Beauchamp and Childress (as cited in Ramcharan, 2014).

- Respecting autonomy. The research participant making an informed decision to be involved. I obtained informed consent from the three research participants having given them information in writing and an opportunity to ask any questions they had about the interview.

- Beneficence. The research will be for the betterment of the public. My aim was to provide a description of how women with complexities in their pregnancy viewed their midwifery care, the aim being to inform improved care.

- Non-maleficence. The research will not cause more harm than good. I have maintained confidentiality and privacy of the participants. I transcribed the recording of the interviews and gave each participant a pseudonym. At any stage the participant could withdraw giving no reason to me. Anyone involved in the transcribing or typing up my handwritten work had signed a confidentiality agreement.

- Justice. The benefits, risks and costs, of the research, are equitably distributed.

The hardcopies of the transcribed data were kept in a locked cupboard. I have stored the tablet which holds the computer files and original recordings in a locked cabinet as stated in my ethics application. The tablet is password protected. The ethics in relation to the data analysis began with checking that my transcribing was accurate and honest (Braun \& Clarke, 2014). At the time of the interview I offered the women the opportunity to review their transcript. Two of the participants declined. The third participant accepted the offer. I did not hear back from her.

As accuracy and honesty are also parts of ensuring the rigour and trustworthiness of the research, I will address this in the next section. 


\section{Rigour}

Both quantitative and qualitative research processes have criteria used to assess the strength of a research (Liamputtong, 2014). She describes the criteria used to evaluate the credibility of qualitative research by explaining four principals.

- Credibility. This refers to whether the findings are credible and actually represent the research participants' experiences. I offered the research participants an opportunity to review their transcripts. The participant who agreed to review her transcript did not respond further. I read and re read the transcripts and listened to the recording several times to check that the transcribing was correct. In the writing up of the research I have made clear the rigour of the processes. The analysis is supported by extracts from the data.

- Transferability. Transferability in research refers to its generalisability to other groups or individuals (Liamputtong, 2013). As this is a qualitative research it is applicable to the participants who revealed how they experienced midwifery care. The data is relevant to the individuals being studied in the specific research setting. Transferability is also affected by the small sample size but it can be used to design further research projects. I make no attempt to say that these findings are transferable. This research is a taster. I hope it will stimulate both researchers and practitioners to explore further the ideas I present.

- Dependability. Liamputtong asks 'Do the findings fit the data' (p.17)? This is ensured by how clearly I documented the research process indicating the consistency, and congruency of the research.

- Confirmability: This demonstrates that the findings are closely linked to information shared by the participants and do not come from the researcher. I shared the data with my supervisor to review and check on how I had coded the data, and compared her emerging themes with mine.

By using the above criteria the research may be evaluated for its trustworthiness. 


\section{Summary}

The first three sections in this chapter justify my approach, the rationale for the approach and then the overall fit of descriptive qualitative methodology. The next three sections are concerned with the research design, recruitment of participants, data collection and analysis. I end with discussion; the research in light of the Treaty of Waitangi; the ethical considerations; and a consideration of the rigour of the study. In the next chapter I discuss my findings. 


\section{Chapter 4: Findings}

This research sought to understand how women with complex needs experienced continuity of midwifery care. I had selected the women because they all had varying types of complexity in their pregnancies, yet still had continued care with their original midwife. The three different types of complexity I chose were pre-existing complexity; acute and unexpected complexity; and social complexity. This chapter presents what I found in my discussions with them. As expected, there were variations in their experiences but there were also some similarities. In order to help understand the themes and the comments of the women, I will first describe the women and their birth stories and then introduce the themes that emerged with excerpts from their talk. Pseudonyms are used throughout.

\section{Description of participants}

\section{Heather's Story}

Heather is married and has two children. I met her six months after the birth of her second child. At the age of twelve she was diagnosed with Type 1 diabetes and is challenged every day to maintain control of her blood sugar by administering an appropriate amount of insulin. She therefore entered the study as a woman with a pre-existing complexity. Heather is confident in her management and does all she can to manage her diabetes so she can be as healthy as possible. She recently acquired an insulin pump which costs her fifty dollars a week. Her support is mainly from her husband and her mother.

Heather knew that the health of her children would depend on her ability and commitment to maintain a tight control on her blood sugars during pregnancy. She was prepared to work hard at this. She understood the complexities of the condition and what she needed to achieve optimal health. To engage a midwife was paramount for Heather as she wanted to have a vaginal birth and understood the midwife's role was to look after her and her baby. Despite information given to Heather that she would not be able to have a midwife, she did manage to find one. She persevered and rang many midwives in the area 
she lived in. She finally found a midwife who was happy to provide continuity of midwifery care for her second baby.

The midwife who had cared for her during her first pregnancy provided continuity of care in the antenatal and postnatal period but not during the labour and delivery. For this she was cared for by the hospital midwives who she had not met prior. Heather developed pre-eclampsia during this first pregnancy and had a forceps birth and a third-degree vaginal tear. When Heather became pregnant with her second baby, she was undecided about finding her own midwife as she had had an excellent experience with the hospital staff midwives during her birth with her first baby. The only reason she initially thought she ought to find an LMC midwife who would provide continuity right through the experience was that she thought her husband could do with support from a known midwife during labour. However, it was the relationship with the second midwife that Heather, thought enabled her to achieve birthing her baby as she wanted. Heather achieved this through a reciprocal relationship of trust with her midwife. She was emphatic that with good diabetic management her body would labour well, providing her midwife was there to support her choices. This was an empowering experience for Heather. She had an amazing experience of trust with the midwife and achieved a vaginal birth.

\section{Kate's Story}

Kate is married and had two daughters. Kate expressed initial fear about being pregnant as she has a congenital heart condition. A congenital heart condition does not necessitate a transfer of clinical care, only a consultation. As her pregnancy progressed her baby was found to be small for gestational age which added to her fear. This is the reason why she was chosen for this study. Kate did not know how her cardiac condition would affect her ability to carry her baby to term. Kate was reviewed at three different DHB's and feared that the different health professionals might not share the history, results or updated plans. The more specialists she saw the greater her fear became.

In her first pregnancy she booked with a midwife who referred her to the secondary service for a plan of care and continued to provide midwifery care. She was referred back to her midwife. Kate was told at her anatomy scan it was 
thought that the baby was small for gestational age; it was not growing well enough. She had her labour induced at 35 weeks as her baby had stopped growing. Her baby became distressed in second stage of labour and she had a ventouse birth with an episiotomy. Her midwife remained present throughout the entire labour; increasing Kate's feeling of being safe, providing explanations and care. She described her labour as a good experience despite there being foetal distress. Kate was able to exclusively breast feed her baby as, although the baby went to the special care unit, she had expressed breastmilk with the support from her midwife.

Postnatally the midwife visited at home which Kate found reassuring. She felt that she and her midwife had embarked on a scary, unknown path together and together they achieved a safe birth.

\section{Felicity's Story}

Felicity was 20 years old and had just had her first baby. Her baby was three weeks old when I met her. She and her partner rented a very small room in a house in a poor neighbourhood. Neither of them was working. Felicity was a smoker, describing herself as an anxious woman which escalated when she was feeling uncomfortable in a strange situation. She believed that girls need extra protection and was hoping for a son.

Felicity accessed her health services at VIBE, a free medical service for teenagers. Once she had a confirmed pregnancy test, she was referred to the midwife who works in the service. She was considered 'low risk' in that she had no pre-existing medical conditions. She did however have several social risk factors and did develop gestational diabetes, necessitating a consultation with an obstetrician and an endocrinologist. Her midwife continued to care for her, was present during the labour and continued care when an emergency caesarean section was required. This included going into the operating theatre to support Felicity and her partner.

The midwife completed six weeks postnatal care and then handed her care over to the well child provider. 


\section{Themes}

As I anticipated, there were some significant differences in how the three women perceived their midwives' care. Despite this, all three midwives played a crucial part in the women's experiences. There were four main themes, each theme having three or four subthemes. Unlike more extensive qualitative research, where there are more participants with themes in common, the themes from my interviews have been brought together. The themes were not common to all three women. I identify differences and similarities between the participants throughout.

\section{The relationship was everything}

This theme was central to the women. All three women thought that the relationship with their midwife was the primary reason for their successful outcomes and positive experience of birth. They also commented that the relationship also seemed important for the midwife. It was also significant for the women that the midwives accepted their perception of their complexity.

\section{Having mutual trust and respect}

The women recognised that trust developed over time right from the first meeting. The three women spoke of some action that the midwife performed which instilled their trust.

For Heather it was that the midwife attended diabetic clinic and met with her on a personal level.

\section{It was the fact that she did come to these hospital appointments with me, and she made such an effort and opened her home to me. I got to know her very, very quickly from there. But it was really nice for him (husband) to have the support of somebody we already knew and who knew us as a couple and could trust that he was doing the right thing, and that I knew what I was doing with my diabetes and they could just focus on me and the baby (Heather)}

Felicity valued the presence of her midwife when her labour deviated from what she had hoped for. Her midwife could have transferred midwifery care to the secondary service where the hospital midwife would have taken over her care but didn't. 
Nah, I couldn't imagine, that would genuinely disappoint me If she just handed me over, I am so happy that she did not hand me off to the hospital you know I have heard that that happens to some people. (Felicity).

Kate interpreted the whole maternity experience as a joint journey. The midwife was there and walked alongside her. She never let her down. She was the essential part of her care.

I think it was really nice to have that one person there, like a core to bring you back *Chuckles*. Give you that - stable - yeah. It's a sort of achievement for both of you. Because she was there every step of the way. It was nice to have those home visits with her. To be like, 'We've been through all of that together'. You built a nice relationship. (Kate)

The women recognized that the continuity of the relationship was crucial for their outcomes.

\section{Grateful for the care}

The women really appreciated having the midwife they knew stay with them. The midwife helped alleviate the fear.

Kate described what she was thankful for; support and translating medical language.

Scary! It was nice to have my midwife there, to ask questions and to support me, because it was really scary. And, she was there - all the time. She was there to answer my calls, and explain things because there is a lot of terminology. I think I would have to make it so I had one midwife - so since I have to deliver in the [name of hospital], I would have a midwife in the [name of hospital]. And if that meant me coming over and having to stay here, I would - I prefer having just the one (midwife) because it's easier! And there is just that one person to bounce off (Kate).

Felicity recognised the value and support that her midwife gave her over the nine months.

She's a good midwife - you know? Like, I don't know, I've never had a midwife before so I have nothing to compare it to, but she's just so nice and I couldn't have got through 9 months without her anyway. I really couldn't have (Felicity).

There was mutual care between both the women and the midwives. The women cared about the midwives and felt cared for by them. 
To know the person you have built a relationship with for 9 months is going to be there when you are at your most vulnerable is just - to me is definitely very important. And when she said that, I almost instantly fell in love with her! I thought that was such a lovely way of thinking about it. From that comment, you could tell she was there to care for you and it was all about you and your health - and she wanted the best outcome for you too. So she wanted to see that through right till the end. I don't know how sustainable it is for other midwives because they've got families and......And I'm forever grateful, and if I had another child I would not hesitate to call her again (Heather).

I liked having the midwife so much. She could have gone home but she chose to stay (with me). She really cares about me. She cares she could have gone home but she stayed for the c section. (Felicity)

\section{Feeling comfortable and close}

The women felt that their care was individualised and that was through the developing relationship with their midwife.

Yeah, I felt really comfortable with midwife. I was surprised, I wasn't expecting to. I'm not a very social, socially balanced person. So, I was happy to be put with her, because she is so easy to communicate with, if you know what I mean. She'd always - what's the word? - made me feel more comfortable. She'd always explain things in a way that wasn't, like, that stopped me freaking out about this pain and that thing. (Felicity).

For Heather and Kate it was about the midwife protecting their dignity when they felt exposed. Both acknowledged that they appreciated this even though they both also commented on the excellence of the hospital midwives.

Even though the hospital midwives were fantastic, I loved the fact that she would be there when you are at your most vulnerable. Felt confident in her ability and experience (Heather).

My midwife. I was quite particular with that, though - with her to be involved with things like that. I didn't - even though the midwives at the hospital were fantastic - I really wanted my midwife, who I felt comfortable with, to do those sort of things. I was comfortable with it, and I was comfortable with her (Kate).

The women thought that because the midwives knew them, they understood what they wanted for their birth.

\section{A calm and composed midwife}

For Kate it was important the midwife was calm when things started to go wrong. Being composed and staying connected and still having her as the core of the relationship mattered enormously. 
My midwife turned to me and explained, 'What's going to happen now, is she is going to give you a small cut to help get the baby out'. So it was nice to have her there, even though she wasn't actually doing anything at that moment. She would turn to me, and give me support. And say - explain to me what was going on. Because when you're in that state, if someone says that to you - you have no clue what's going on. "Laughs* and then, as soon as the baby was born, she really took over and saw the baby and made sure the baby was okay. They did have to put baby on oxygen straight away and I think the paediatrician. But the midwife was always very good at explaining things and giving me support. I just remember her being very - making sure I was okay. So very, 'This is happening' - but staying very calm and composed. Even though, things were very crazy at the end - and the obstetrician had to step in - she was still very there. (Kate)

\section{Appreciated the midwife}

Kate and Felicity were both facing emergencies which was not what they had expected from their birth plan. This would have increased Kate's fear and Felicity's anxiety as there is a physiological cognitive response to fear. That the midwife remained calm kept them connected to the birth of their baby and made them feel they were in safe hands.

I expected normal labour and normal everything - but it just didn't happen. In the end, I was quite happy with what happened as it was quite calm: Yeah she did, I was glad because she was basically the person who made me feel confident about it all. (Felicity)

\section{Knowing what was happening was important}

The women all valued that the midwife kept them well informed during their pregnancies. This was even more important for these women as their pregnancies and births were complex. There were also a lot more health professionals involved requiring someone to hold all the information and to communicate in a clear and relevant way. The midwives also played an important role in preparing the women for what might happen.

\section{Clarifying the midwifery role}

Despite midwifery continuity of care having been in place for almost thirty years neither Heather nor Felicity were aware of the full role of the midwife. This could have been confusing for them as, for example, Heather had asked her friends who were also type 1 diabetics how to find a midwife. She really wanted a midwife to look after her and her baby. She wanted to develop a relationship with a midwife. She was disappointed that it seemed that she would be unable 
to engage the service of a midwife and would have to be cared for by the diabetic 'team'.

A couple of friends said I wouldn't be able to have a midwife. So, when - I heard about their experience and it wasn't fantastic, they didn't enjoy the process at all because they were just - they'd go to the waiting rooms on the clinic days and they'd wait for hours to see somebody they didn't know. So there was no consistency in the care, in that respect. So I had no - when I eventually felt pregnant, I didn't think I would get a midwife (Heather).

Felicity was also misinformed about maternity care and didn't really appreciate how a midwife could be

Oh no, no. But, it's generally just - Vibe, you know, you get taught about it at school. It's for aged 16-24, then you can't go there anymore, or you can go but it's not free anymore. Or something like that. Or it's a free clinic or something like that. I find it generally the easiest place to go to, because GPs aren't cheap. *Chuckles*. Yeah. Which is also why I decided to go for a midwife, because GP visits you're going every week or so, or every two weeks when you're pregnant and it's just like, a lot of cash! (Felicity)

Kate didn't really comment on this. She had booked in with a midwife from the beginning. However, despite the fact that the role of the midwife was not clear to each of them at the start, they were all very appreciative and all commented that they would want to have that midwife care for them again.

\section{Interpreting medical information}

These mothers all really valued the role that their midwife played in helping them understand what was going on

There were some differences between Kate and Felicity who were having their first baby and Heather who was having her second baby. Of the three, Kate expressed most fear about not knowing what was going on and fear of the unknown. She was keen on the information and understanding it thoroughly; interestingly it was her midwife that she turned to for the explanation and interpretation of medical terminology.

It was tricky, but it was good to have two - from an obstetrician side of things and then the midwife side of things. Because the obstetrician can be very medical and have the midwife bring it back home, explain things and be a little more in touch with you. Where the obstetrician although, I had a fabulous obstetrician, it was very medicalised which can be very understanding. So, it was nice to have the midwife, 
sort of bounce things back at me. Explain what's going on, so that was nice. (Kate).

Heather felt fearful around the obstetrician's communication style. The obstetrician was really blunt with her explanation and information sharing on the outcome if Heather did choose to have another vaginal birth. This is the only time Heather spoke of any risk regarding her pregnancy and that was the risk of another third-degree tear. Heather and her midwife were able to mitigate that risk by discussing it and the communication style of the obstetrician.

Communication becomes so important.

So you get all this fear of what is going to happen. I had the obstetrician saying to me, 'If you have a natural birth, you're going to tear your sphincter' - she said that about 3 times to me and it was just - it was just it was awful to hear, I know, but because there are always going to be risks involved in that. And she wasn't pushing me to have a caesarean, she was just telling me the risks and it was a very blunt way of saying it. It was just, if you have a natural birth you could tear your sphincter... *both chuckle* and, it was really nice that the midwife, was there to hear that. (Heather)

Felicity never mentioned an obstetrician or any interaction with the medical team including the diabetic team. She stated that her midwife

Yeah, she was - she's just really on point with everything. She'd always tell me - I didn't have to ask anything, really (Felicity).

Felicity however focussed on her needs once the baby was born; grateful for her midwife's referral to the social worker.

\section{Listening and teaching}

Along with the interpretation of the medical information, the women stressed the importance of really good communication in which they felt heard and had assistance with the teaching and coaching from their midwife.

Heather had sustained a third-degree perineal tear after her forceps delivery with her first baby. Her midwife was present when Heather and the obstetrician had a conversation about risks for her next birth. Heather valued the presence of her midwife, the instructions on how to do perineal massage and coaching on how to control the birth of her baby's head to prevent tearing. She felt that the midwife supported her self-determination. 
We left that, we knew the obstetrician, we knew that she says things like that quite bluntly. And you take it with a grain of salt, and then you process it later. Or - and as soon as she left she said, 'Oh, I wouldn't even worry about her'. So I think that, you Yup, she talked about the massage and that kind of thing. Yeah (Heather).

And just when everything was going on, and the obstetrician did say that - 'I'm going to do an episiotomy'. My midwife turned to me and explained, 'What's going to happen now, is she is going to give you a small cut to help get the baby out'. (Kate)

Both Kate and Heather were taught how to hand express during the antenatal period. Their midwives supported this practice and both babies who were at high risk for hypoglycaemia were exclusively breast fed.

The midwife suggested before going into labour - and even before coming to - knowing that I was going to be induced. Was expressing, and putting it into syringes. And baby, pretty much used all of that. I had a good stock pile because I started quite early on. For the first few days where she really struggled to breastfeed, they gave her that in SCBU - so that was a good - (Heather).

Felicity however commented only on the fact that her midwife did everything Midwife did everything for me (Felicity).

\section{She had the big picture}

The women thought the midwives had an oversight of the entire situation. They trusted their knowledge; they never questioned it.

For Kate it was the continual communication from her midwife in the emergency situation that was important.

Even though she was not physically doing something she would tell me exactly what was going on. Gave good advice on things you don't think of or don't know (Kate).

For Felicity her midwife knew what she needed.

And I went to see midwife in the following week or within a couple of days. Then, she sent me for my dating scan or something. So, I didn't really know how far I was along when I met her. She did everything for me. (Felicity)

Felicity had trust that her midwife had the knowledge and capability to look after her. 
For Heather, her midwife was physically present at all her antenatal appointments so definitely had the board overview.

She went absolutely above and beyond - she came to every single one of my pregnancy diabetic appointments with me. So, not only did she schedule the appointments in between the specialist clinic, she actually came to the specialist ones with me which included seeing the diabetes specialist, the endocrinologist and the obstetrician. (Heather)

\section{Power was managed and balanced}

Power relationships with care givers varied among the women. But for all the women power issues, to some degree were apparent.

\section{Being empowering and uplifting}

Heather held the power in the management of her diabetes. She actively sought midwifery care despite being told she couldn't. She was, able to have an equal power relationship with the midwife. In fact, in the end, the trust relationship enabled empowerment for Heather
And she was all about, 'It doesn't matter the size of the baby, I have confidence you will be about to birth the baby - no matter what the size is'. And that for me, was really empowering. That was just what I needed to hear, and what I needed to hear first time around - you hear all these, 'Your baby has a big tummy'. So you get all this fear of what is going to happen. (Heather)

The acknowledgement and support of the midwife really enabled Heather to reach her full potential. She was able to birth normally despite her complexity and despite medical protocols.

I could stand. I gave birth standing up. I had the bed raised and I had a tri-pillow. But, the whole experience at the end was just so different. So empowering as well. That I could do it, my body could actually do it. So I think that, you know having the midwife there just acknowledged the way I was feeling as well. Because she was encouraging me, she was empowering me so I felt strong enough, I felt like things were going to go well. And you need to remain positive. (Heather)

\section{Advocating}

The other two women made reference to power differently. Advocacy was important. The midwives used their own power to protect the women from harm and also to make critical decisions when necessary. 
Even though it was a stressful labour I felt not calm but safe because the midwife was really good at making sure that I was alright and explaining everything. And got the obstetrician at the right time. (Kate)

For Felicity it was advocating for her to have the right equipment for her baby including the pepipod (safe sleep container which fits on the bed) for safe sleeping her baby.

Oh she was going to, she actually got me a cot but it ended up being too big for the room, because that's all the space we have. So, we couldn't find a king size single too - she ended up getting us a bassinet which we were bummed out because we couldn't use it so we ended up getting this from somebody (pepipod)... might've been my social worker. (Felicity)

Yeah she spoke to me about everything, and set me up with everything. She's the one who set me up with my social worker, who is really just there for anxiety - she's going to help me at the doctors. Midwife set me up with lots of little support networks, like this company who bring you food when you have newborns. We got some volunteer people to drop us food packs to heat up in the microwave, which was really convenient. Lifesaving companies, they're onto it all the midwives. (Felicity)

Felicity did not share with me that she made any decisions about her care. She liked it that the midwife did everything for her. However, Felicity attended all her antenatal visits, appreciated the support both physical and mental and was able to advocate for herself in phoning an ambulance. It felt like she was not used to receiving things or support.

\section{Sharing decision making}

The women developed confidence in themselves through information sharing from the midwife. This enabled them to take an active role in decision making. For Kate it was the decision that she was able to ensure that the midwife was there for the start of her induction of labour to perform the vaginal assessments.

I was quite particular with that, though - with her to be involved with things like that. I didn't - even though the midwives at the hospital were fantastic - I really wanted my midwife, who I felt comfortable with, to do those sort of things. (Kate)

For Heather it was about a balance of reciprocal sharing of information which enabled joint decision making.

Yeah I think we definitely learnt from each other. We had - I had the desire to have different kind of birth and she wanted to learn more 
about diabetes too. Equal partnership. So, took a lot on board with that as well (Heather).

Confidence building is a significant outcome for continuity of care as it enables the woman to be a participant in her own care.

Felicity may have taken an active role in decision making but did not speak about this. Her experience of continuity was more about being taken care of.

\section{Extra care was needed}

For the two women who had existing medical conditions it was even more important for them to have a midwife. It did seem that for one of the participants at least, the more they needed a midwife, the harder it was to find one.

Heather who knew she has risk factors even before she became pregnant had a real challenge in engaging a midwife in two ways. Firstly, her estimated due date fell over the Christmas period when community midwives are taking a summer break and there are less available, and secondly, she has Type 1 diabetes.

So when I went to the pregnancy clinic and saw the diabetes team there, they said to me that I need to find a midwife. So that came as a surprise to me to start with. But I was quite pleased with that. But they said that there would only be 2 midwifes in the [region in NZ] that would look after me who had experience in diabetes, which is funny because they can't really look after my diabetes anyway. They're there to look after me and the child, and the diabetes clinic was there to look after diabetes side of things (Heather).

Heather checked on the Find Your Midwife website.

When I read her profile she was all about natural, with no interventions and that kind of thing. And I said to her, 'Look, I am a diabetic, my birth could be very medicalized. My first delivery was with forceps and I needed a lot of drugs'. I just said to her, 'You have to be comfortable that my birth could be quite medicalized as well'. (Heather)

Heather sounded out this midwife, challenging her attitude to complexity and. on whether she could trust her.. She was determined to find a midwife and this relationship became the vehicle that Heather needed to fulfil her desire of being in control of her birth experience. 
Kate did not address this in her interview. Felicity did not look for a midwife; she was referred to the midwife who worked at Vibe. She did say that she did not know anything about midwives or how to engage their service.

\section{She was always there}

The three women commented on the continued presence and availability of their midwife. For Felicity the most important part of the relationship was this.

Yeah, she didn't hand me off to anyone, she continued seeing me. That's why I didn't want a GP, because they go, 'Oh yeah, blah blah, go away'. They don't really give you advice or support, they're not really there for you or anything. (Felicity).

This was different to her previous experience with health care professionals.

Kate also felt that the midwife was always there.

She was always there could ask all sorts of questions. I saw the midwife more than usual (Kate). - I think I had weekly appointments with my obstetrician and weekly with my midwife *Laughing*, so it was one day here, then a follow up with my midwife or vice versa. Yes. I think a little bit more than your normal pregnancy, just because it was complex. It was a lot of the time - to follow up what happened with the obstetrician with the scans. Because I had weekly scans, especially towards the end. I think it was because of the uncertainty, because it was my first pregnancy and everyone was just keeping a close eye on me - and I really appreciate that my midwife took the time to do that. And that was what was really nice, to have one midwife follow me throughout - because even though I had all these other things - the scans, the obstetrician, I had to go to [the tertiary hospital] for a special scan. And see a specialist there because of my heart. I think it was really nice to have that one person there, like a core to bring you back *Chuckles*. Give you that - stable - yeah. (Kate)

It was through the relationship that the women appreciated their continued presence.

\section{The midwife relieves fear and anxiety}

Because of the relational aspect of continuity the women felt known by the midwife and therefore this eased their fears; they felt cared for by the midwife. Felicity acknowledged the impact of her midwife accompanying her to theatre.

I get really bad anxiety; so for the midwife to come to theatre with me eased my anxiety and I was terrified. They care they actually care. Midwife set me up with a social worker who was for my anxiety. Social worker is going to help me when I visit the doctor (Felicity). 
For Kate a perceived loss of her clinical information triggered anxiety and fear in her.

Discontinuity of care increased my fear that all information would not be shared. Worried that I would not get everything that I needed.

(Kate)

Despite the midwives' constant presence Kate decided that to deal with her anxiety around loss of information, she would keep a record of her visits to various DHBs and medical staff. The midwife did not relieve her fear sufficiently and Kate had the confidence to sort this out herself. Both Kate and Felicity overall found that the fear was relieved by the presence of the midwife. Loss of informational continuity caused a continued niggle for Kate.

\section{Managing the three-way consultations and the information}

Two of the women had their midwife attend the consultations with the medical staff. Heather did not expect this at all but really appreciated it and saw this time together as important in developing their relationship.

Care went beyond expectation midwife attended every diabetic specialist appointment. (Heather).

For Kate her midwife attended all the three-way conversations;

And just having someone I can go back to and ask questions - not having a different person at different stages - having that one person to come with me to all of the specialist appointments, having them go through the scan results with me. (Kate)

Even attending the three-way conversations did not help the midwife keep up to date with the information.

Because I found in the beginning, everyone was really good at sharing information. A lot of things were online, so they could print off specialist things or, people would email things - I think just towards the end I started to keep things. (Kate)

Felicity did not speak of any involvement with medical staff at all.

\section{Summary}

My interviews with these three women were informative. Despite that they were different in their types of complexity, there were themes they shared in common, but with some differences in how they were expressed. The four 
themes that emerged indicated that the relationship with the midwife was very important, that the midwife played a big role in providing information for the women, that she facilitated a balancing of power and that because of their level of complexity they were enormously grateful for the extra care. They felt they achieved a good outcome despite the complexity and all three commented that they would ask that midwife to be their midwife again. 


\section{Chapter 5: Discussion}

This research was a small study to open the discussion about the experience of women with complexity who have continuity of midwifery care. I chose to interview three women with varying degrees and types of complexity or 'risk'. In this final chapter I discuss the themes identified in relation to the current literature and considering this, identify the key issues and implications that emerged. I also address the limitations and advantages of this research, discuss any possible recommendations and identify future research in the area.

\section{The themes and the literature}

The core concept of this study is continuity of care. Its contribution is cited in relation to high quality maternity care (Sandall et al., 2016 \& Wickam, 2015). Quality maternity care is important for all women regardless of whether they are low risk or whether they have complex pregnancies. In listening to the experience of continuity for women with added complexity, this study uncovered four themes. The first is that the relationship was everything; the second is that knowing what was happening was important; the third that power was managed and balanced; and finally, for these women extra midwifery care was needed. In light of these themes it is important to go back to the existing literature to see how they are either similar or vary from what has been discussed previously in order to identify the contribution this study could make.

\section{The relationship is everything}

There was a high level of congruency between this theme and the existing literature. The literature on continuity of care shows that relationship is central to continuity of care. For example, a metasynthesis of thirteen qualitative studies on what women value about continuity of care was undertaken by Perriman, Davis, and Ferguson (2018). The purpose was to generate a more comprehensive view of continuity of care from this collective pool of data. Of significance for my study is the definition used for continuity of care was similar to the one I have used in this study. "One midwife (and her backup colleague) providing midwifery care throughout the entire childbirth experience" (Pairman \& McAra- Couper, 2015, p.398). It was thought that the quality and supportive 
relationship that developed when continuity was provided contributed to the success of this model. There was also considerable congruity about this in other studies in which the authors commented that continuity of care allows time for relationships to develop and helps to build trust (Boyle et al., 2016; Davison et al., 2015; Dove \& Muir-Cochrane, 2014; Jenkins et al., 2015; Lewis et al., 2017). Women voiced that the development of trust with their own midwife increased not only their sense of safety but the reciprocal trust that the midwife had in their decision making and their abilities. Midwives reported that trust between the women and themselves was the most important aspect of the relationship in negotiating risk. Other authors also commented on the growing evidence that the quality of the relationship, specifically the development of trust, is crucial in negotiating complexities in the maternity episode or at the primary/secondary interface (Dove \& Muir-Cochrane, 2014; Homer, et al., 2017; Skinner \& Maude, 2016). Reciprocal trusting relationship between the woman and midwife often revealed social risk and complexity (Dove \& Muir-Cochrane, 2014). In contrast to this Dove \& Muir-Cochrane (2014) contradicted my findings noted that women with high risk pregnancies did not benefit from continuity of care as they thought they required exclusive obstetric care.

However Davison, Hauck, Bayes, Kuliukas and Wood (2015) interviewed women who were defined as high risk by the obstetric team. Their only option was to receive fragmented obstetric care because of their risk status. The women felt that this was unsafe for them and they deliberately sought the service of a private midwife to provide the relational aspect of continuity of care they considered optimal for their childbirth process. These women chose to birth at home as it felt the safer option. Hauck et al., (2018) on the reasons women of all risk status chose to birth at home was to experience the relational aspect of continuity of midwifery care. Homer et al. (2017) further claim that relational continuity of care in a caseload model of midwifery care is able through trusting relationships to break down barriers to accessing care.

\section{Knowing what was happening was important}

Some of the literature I found addressed this issue. In the Netherlands, for example, the primary midwives provide continuity of care to low risk women only. If a risk factor develops, the women's care is handed over to the clinical 
midwife in the hospital setting for further management. Therefore there is always a discontinuity of care. de Jonge, Stuijt, Eijke and Westerman (2014) interviewed women who had had negative birth experiences in this model of care. They found that women felt unsafe when a handover from the primary midwife to the clinical midwife occurred. This discontinuity of care caused fear and anxiety that information of their birth plan and what was important to them would be lost. Jenkins et al. (2015) in their examination on whether women desire continuity of care found that information sharing was crucial in the continuity of care model. For some women having continuity of information sharing was best provided by a single provider. This is also reflected in my findings. The more health professionals involved in care the more inconsistent and difficult it is to keep track of the information. Lewis et al. (2017) noted that woman having their first baby had a higher need for information gathering as they felt they were entering a journey of the unknown. This process was intensified in my findings by the added uncertainty in the outcome because of the clinical or social complexity.

\section{Power was managed and balanced.}

The literature supported my findings on how power was balanced. In a study by Sandal et al. (2016), the women who had continuity of care were highly satisfied with their control in labour; coping physically and emotionally. They commented that trust was central to their sense of empowerment and that this relationship led to feelings of control. Dove \& Muir-Cochrane (2014) in their study commented that the women wanted their midwife with them even when the core midwife would not ring their own midwife to come in when requested. Their own midwife's support was necessary for them. Lewis et al. (2017) found evidence that women at the start of the continuity relationship expressed the idea that midwives had the control and power. However this was balanced by the evolving trusting relationship which enabled the women to become more self-determining as the relationship progressed.

\section{Extra midwifery care was needed}

This was a point of departure from the literature. My research found that all three women acknowledged that the extra time and care given by the midwives was central in developing the relationship and trust because of their complex 
needs. In researching the literature to see if this had come up before, I found only one piece of New Zealand research by Currie and Cornsweet Barber, (2016). They asked women who were pregnant with a medical complication about their experience of birth. One of the themes noted from their study was the importance of the relationship with the midwives. I noticed one of the quotes in this theme was from a woman describing her experience as "I think they went a bit beyond" (Currie \& Cornsweet Barber, 2016, p.37). However this theme was not developed further or commented on. The women in my study all appreciated and acknowledged this extra time, which has implications for midwifery care where complexity increases.

\section{Key messages from the research}

There were three key messages from this research.

\section{Continuity is even more important where complexity increases}

All the aspects of midwifery care that are important for low risk women in a continuity of care model are also just as, if not more important for women experiencing complexity. Women with complexities require extra care whether that is in time spent with the woman and/or referring to appropriate health professionals and/or attending specialist appointments with them. Women who have existing complexities or who develop complexities in their pregnancies are required to deal with frightening information about unwanted outcomes for themselves or their babies; which increases their fear and anxiety. Currie and Cornsweet Barber (2016) note the negative effects fear and anxiety have on women with complexities. Fear and anxiety increase the chances of a woman acquiring psychological distress during the maternity episode. It is through the developing relationship in a continuity of care model that individual women's feelings are understood and integrated into care by the development of trust. It is through a trusting relationship that women feel safe and empowered. This can be understood as reducing aspects of risk. The women in my study realized that their complex status enhanced their care as they had extra midwifery input. This is a positive aspect of complexity as Lee, Holden and Ayers (2016) discuss in their paper on high risk women. 


\section{The woman defines the complexity; the midwife becomes the central holder of that interpretation}

It was clear from talking with the three women in the study that they did not have the same attitude to risk as the midwives. I was looking for variability and it was there. This is also found in the literature. Lee, Ayers, and Holden (2015) indicate the evidence that women and health professionals do not view risk in the same way. Women interpret their risk status through many sources including friends, families and the internet. Holness (2018) confirms this by stating there is no definition of high-risk pregnancy because risk is perceived differently by mothers and health care professionals. Risk is a category which is not definable. It is not a useful term for midwifery or women as there is no common understanding of the meaning. The woman understands the complex nature of her world and therefore it is the women who will benefit from the relationship of continuity of care as the midwife comes to understand how women interpret the complexity of their lives. As Lee, Ayers and Holden (2014) note, women who have long standing medical conditions use their understanding of their condition in controlling the outcome. Frustration can occur if their management of their own condition is called to question by health professionals. A good example of this is the woman in my study who had managed her type 1 diabetes for years. These women know their bodies and their responses best and may be resistant to inexperienced health professionals managing them. However in a continuity of care model the midwife can support the self-determining nature of the woman. It was through interviewing the women a clearer picture of their complexity emerged and how they interpreted it. I understood how they dealt with it and what made them feel safe.

Increasingly there are a number of women who would not have achieved pregnancy before but with advances in medicine and artificial reproductive technology the situation is very different. Continuity of care is surely important for these cases too.

It is important for women to share their understanding of complexity so the midwife can start a trusting relationship with the mother where she feels included in the decision making and has control over what is happening to her. 
If we look at how complexity was defined in chapter 1 , is there anyone in the world who is not complex? How does a midwife decide when a woman is complex and how and when does a midwife decide not to look after her? These questions are pretty central for midwifery and for women.

I would contend that women who have complexities as defined by the system and in the current cultural context, really need continuity as much if not more than those with less complex scenarios. "Midwifery claims a position of "with women' within a professional relationship" (Skinner \& Maude, 2015, p38). Midwifery is holistic; combining an understanding of the social, emotional, cultural, spiritual, psychological and physical ramifications of women's reproductive health experience (New Zealand College of Midwives, 2015).

\section{Separating off women who can and cannot have midwifery continuity is problematic}

As discussed in the introduction and noted in the maternity report of 2017(Ministry of Health, 2019b), childbirth has become more complex. There has been a significant increase in elective caesarean births and therefore a decreasing number of women having spontaneous vaginal births. Half of the women having a vaginal birth had some form of obstetric intervention during labour and birth. There is also an increase in women who are obese at their first booking visit. Women living in the most deprived socio economic neighbourhoods also have a higher incidence of obesity. These factors increase complexity and the need for transfer of clinical care.

The referral guidelines give the option to midwives to transfer midwifery care to the secondary service if they believe that they don't have the skills, knowledge and experience to provide optimal care. If the woman does not consistently have the option of continued midwifery care in complexity, one wonders how this affects their experience of the birth of their baby. Perhaps the education of student midwives needs to be modified to encompass the rapidly changing profile of pregnant women and increasing complexity of midwifery practice. Ongoing midwifery professional development needs strategic updating to empower midwives to support complex needs. This raises potential implications 
for the sustainability of: the current structure of the maternity service and lead maternity midwifery care

Given the steady increase in complexity a woman has a much greater chance of her midwifery care being handed over from her primary midwife to the secondary and tertiary midwifery services. Here is the dilemma. We need to adapt the current model of midwifery to encompass equitable access of choice for women with complexity.

\section{Reflections on the research process}

I thought that a qualitative perspective was a good fit for this small exploratory study. It specifically encouraged the women to talk about their own experience of receiving care from their midwife and allowed different aspects of context to emerge. The three women were all different, and the study is very small so it is not possible to make generalizations. However, this study does indicate that women have different needs and expectations of their midwives.

Although I had no doubt about the chosen method, I had real difficulty in talking to women about their midwifery experience as it is not something that I commonly do. I do not generally enquire about the quality of midwifery care women have been provided. I also wondered how it would be listening to women's experiences if they perceived their care as poor practice. Thankfully, I did not hear any of that. What it did leave me with was a feeling of being immensely proud of my profession.

One of the challenges that I had was that the women and I had different understanding of certain aspects of interpreting risk. It was really good for me to learn what risk meant to them; what living with diabetes entailed and what the midwifery support felt like. It was easy to find women to talk to but I found it quite time-consuming in transcribing the data and I wish I had put more thought into the questions and discussion part. However, I realize that the more questions I asked the more I would have led them down the track of what I wanted to hear. I wanted to be quite silent in the interview. I am committed to continuity of care so did not want to influence their answers. 
Upon reflection, I had no idea at the start of the study just how complicated it would prove to be. The lack of a universal definition of continuity of care, interfaced with complexity versus risk, resulted in me searching more broadly than I had anticipated. There are a significant number of models of maternity care expounding how continuity of care, especially in low risk pregnancy, produces better outcomes.

\section{Suggestions}

This was a very small introductory piece of work, just scratching the surface of what is a progressively important issue. Because of its scope and size, it would be presumptuous to come up with concrete recommendations for a change in practice. However, from my experience of being alongside midwives and the women we care for whose requirements become more complex, it is becoming apparent that we need to be proactive in creating models of midwifery that meet the needs of women and are sustainable for midwives.

- We need to know a lot more about this issue. More research from multiple perspectives is desirable so we can provide the right care to the right people at the right time.

- We need to look at increasing midwifery efficacy by re-claiming a culture of women centred care, based on relationships and individual needs of women.

- Referral to other health professionals should be collaborative and should prioritise the facilitation of continuity of midwifery care where feasible.

- Midwives should be recompensed for the extra time they spend caring for women with increased complexity

\section{Concluding statement}

What has concerned me the most in my midwifery practice recently and which eventually led to this study was the puzzle of why aren't we providing the highest quality of midwifery care to the women who need it the most? The intangible notion of trust is fundamental in the relationship between midwife and woman and that can only be truly developed over time in a continuity model of 
care. This is the basis of providing comprehensive/holistic midwifery care targeted to that woman, no matter what her complexities are. It seems that it is this relationship of trust, facilitated by knowing the midwife over time that provides better clinical and social outcomes. 


\section{Appendix A}

TE WHARE WÃNANGA O TE OPOKO O TE IKA A MĀUI

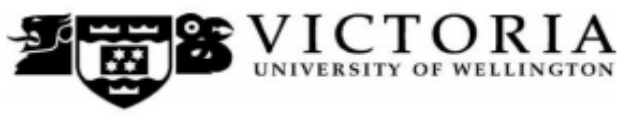

MEMORANDUM

0-4-463 6028

Email judith.loveridge@vuw.ac.nz

\begin{tabular}{l|l}
\hline TO & Eleanor Martin \\
\hline FROM & Dr Judith Loveridge, Convenor, Human Ethics Committee \\
\hline
\end{tabular}

\begin{tabular}{l|l}
\hline DATE & 30 November 2017 \\
\hline PAGES & 1 \\
\hline
\end{tabular}

SUBJECT $\quad$ Ethics Approval

Number: 25306

Title: Continuity of Midwifery Care in Collaborative Practice: A Qualitative Description

Thank you for your application for ethical approval, which has now been considered by the Human Ethics Committee.

Your application has been approved from the above date and this approval is valid for three years. If your data collection is not completed by this date you should apply to the Human Ethics Committee for an extension to this approval.

Best wishes with the research.

Kind regards,

\section{A. honeidge}

Judith Loveridge

Convenor, Victoria University of Wellington Human Ethics Committee 


\title{
Appendix B
}

\author{
TE WHARE WĀNANGA O TE ŪPOKO O TE IKA A MĀUI

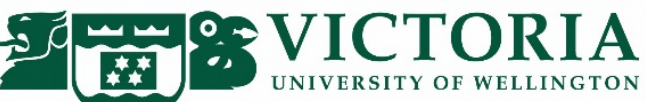

\section{Continuity of Midwifery care in collaborative practice: A qualitative description.}

\section{INFORMATION SHEET FOR PARTICIPANTS}

Thank you for considering taking part in this research. Please read this information before deciding whether to go ahead.

My name is Eleanor Martin and I am a Masters student in Midwifery at Victoria University of Wellington. This research project is work towards my thesis.

This project aims to describe some of the factors which women who develop complications during childbearing identify about their midwifery care. Some midwives hand over the care of women with complications. I have invited you to take part because your midwife stayed with you and continued to provide care. I would like to know what that felt like for you. It is known from studies that women who have straight forward pregnancies and who have continuity of midwifery care have better outcomes. Not much is known whether this kind of care from a midwife is what women want when their pregnancies are at risk. This is what I want to find out.

You have been invited to participate for two reasons;

- you have had a midwife follow your care from the time that you booked to the end of your postnatal period;

- you experienced some complexity in your childbearing.

If you agree to take part I will interview you at your home or in a different location which suits you. I will ask you questions about your experience of the midwifery care that you received during your childbirth experience. The interview will take about an hour to an hour and a half.

With your permission I will audio record the interview and write it up later. You can choose to not answer any question or stop the interview at any time, without giving a reason. You can withdraw from the study by contacting me at any time before 31 March 2019. If you withdraw, the information you provided will be destroyed or returned to you. 
This research has been approved by the Victoria University of Wellington Human Ethics Committee 0000025306.

This research is confidential. This means that only I and my supervisors will be aware of your identity. The research data will be combined and your identity will not be revealed in any reports, presentations, or public documentation. Confidentiality will be preserved except where you disclose something that causes me to be concerned about a risk of harm to yourself and/or others.

Only my supervisors and I will read the transcripts of the interview. The interview transcripts, summaries and any recordings will be kept securely and destroyed on 31 December 2018 which is the date that the work is completed.

The information from my research will be used in Masters and/or academic publications and conferences.

You do not have to accept this invitation if you don't want to. If you do decide to participate, you have the right to:

- $\quad$ choose not to answer any question;

- $\quad$ ask for the recorder to be turned off at any time during the interview;

- $\quad$ withdraw from the study before 30 November 2018

- $\quad$ ask any questions about the study at any time;

- $\quad$ receive a copy of your interview recording;

- $\quad$ receive a copy of your interview transcript;

- $\quad$ read over and comment on a written summary of your interview;

- be able to read any reports of this research by emailing the researcher to request a copy.

If you have any questions, either now or in the future, please feel free to contact either:

\section{Student:}

Name: Eleanor Martin

School: Victoria University

martinelea@myvuw.ac.nz

Mobile number 0211239471

\section{Supervisor:}

Name: Dr Joan Skinner

Role: Research Associate

School: Victoria University

Joan.Skinner@vuw.ac.nz

\section{Human Ethics Committee information}

If you have any concerns about the ethical conduct of the research you may contact the Victoria University HEC Convenor: Associate Professor Susan Corbett. Email susan.corbett@vuw.ac.nz or telephone +64-4-463 5480. 


\title{
Appendix C
}

\author{
TE WHARE WĀNANGA O TE ŪPOKO O TE IKA A MĀUI

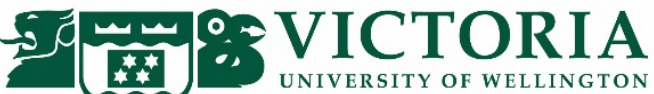 \\ 4 \\ Continuity of Midwifery care in collaborative practice: $A$ \\ qualitative description.

\section{CONSENT TO INTERVIEW}

This consent form will be held for 10 years.

Researcher: Eleanor Martin, Graduate School of Nursing, Midwifery and Health, Victoria University of Wellington.

- I have read the Information Sheet and the project has been explained to me by Eleanor Martin. My questions have been answered to my satisfaction. I understand that I can ask further questions at any time.

- I agree to take part in an audio recorded interview.

I understand that:

- I may withdraw from this study at any point before 31 March 2019, and any information that I have provided will be returned to me or destroyed.

- The identifiable information I have provided will be destroyed on completion of the study, 1 July 2020

- Any information I provide will be kept confidential to the researcher and the supervisor.

- I understand that the results will be used for a Masters and/or academic publications and/or presented to conferences.

- $\quad$ My name will not be used in reports, nor will any information that would identify me.

- I would like a copy of the recording of my interview:

- I would like a copy of the transcript of my interview:

Yes No

- I would like a summary of my interview:

Yes No 
- I would like to receive a copy of the final report and have added my email address below.

Signature of participant:

Name of participant:

Date:

Contact details: 


\section{Appendix D}

\section{Interview Prompts}

Continuity of Midwifery care in complexity: A qualitative description.

$\underline{\text { Interview questions/prompts }}$

Tell me about your experience of midwifery care.

How did your midwife discuss the issues and the uncertainty that you were experiencing?

Were you satisfied with the information that your midwife provided to you?

What were the best things about having a midwife you knew with you?

What were the challenging things about having the same midwife?

What made you anxious?

Was there an indication from the midwife that she may be required to hand over your care and if so how did that make you feel?

What role do you think your midwife filled for you? 


\title{
Appendix E
}

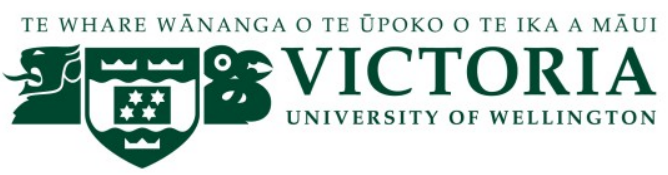

\section{Transcribing Confidentiality Agreement}

\author{
Project Title:
}

Principal

Investigator:

I , agree to ensure that the

[audiotapes/videotapes] I transcribe will remain confidential to and myself.

I agree to take the following precautions: 
1. I will ensure that no person, other than

, [hears/sees] the recording.

2. I will ensure that no other person has access to my computer/device.

3. I will delete the files from my computer/device once the transcription has been completed.

4. I will not discuss any aspect of the recording with anyone except

Signature:

Date: 


\section{References}

Association of Midwives. (1986). Save the Midwives. Retrieved from Unknown website: https://teara.govt.nz/en/zoomify/27920/save-the-midwives

Beake, S., Acosta, L., Cooke, P., \& McCourt, C. (2013). Caseload midwifery in a multi-ethnic community: The women's experiences. Midwifery, 29, 9961002. https://doi.org/10.1016/j.midw.2013.01.003

Boyle, S., Thomas, H., \& Brooks, F. (2016). Women's views on partnership working with midwives during pregnancy and childbirth. Midwifery, 32, 2129. https://doi.org/10.1016/j.midw.2015.09.001

Brand, S., \& Pollock, K. (2018). How is continuity of care experienced by people living with chronic kidney disease? Journal of Clinical Nursing, 27, 153161. https://doi.org/10.1111/jocn. 13860

Braun, V., Clarke, V. (2014). Successful Qualitative Research a practical guide for beginners. SAGE.

Braun, V., \& Clarke, V. (2006). Using thematic analysis in psychology. Qualitative Research in Psychology, 3(2), 77-101. https://doi.org/10.1097/00005053-199205000-00001

Briscoe, L., Lavender, T., \& McGowan, L. (2016). A concept analysis of women's vulnerability during pregnancy, birth and the postnatal period. Journal of Advanced Nursing, 72(10), 1-34.

https://doi.org/10.1111/jan.13017

Cauldwell, M., Patel, R., Steer, P., \& Gatzoulis, M. (2016). A time for greater investment into care for pregnancy and heart disease. International Journal of Cardiology, pp. 642-643. https://doi.org/10.1016/j.ijcard.2016.06.292

Cluett, E., \& Bluff, R. (2006). From Practice to Research. In R.Cluett \& E. Bluff (Eds.), Principals and Practice of Research Midwifery (2nd ed., pp. 14-31). Churchill Livingstone.

Colorafi, K. J., \& Evans, B. (2016). Qualitative Descriptive Methods in Health Science Research. Health Environments Research and Design Journal, 9(4), 16-25. https://doi.org/10.1177/1937586715614171 
Currie, J., \& Cornsweet Barber, C. (2016). Pregnancy gone wrong: Women's experiences of care in relation to coping with a medical complication in pregnancy. New Zealand College of Midwives Journal, (52), 35-40. https://doi.org/10.12784/nzcomjnl52.2016.5.35-40

Daly, B., Raiman, I., \& Goodson, J. (2017). Screening for diabetes in pregnancy in a regional area with a high Māori population. The New Zealand Medical Journal, 130(1450), 25-31.

Davis, D. \& Hunter, M. (2015). The place of birth. In S. Pairman, J. Pincombe, C. Thorogood, S.Tracy (Eds.), Midwifery Preparation for practice (3rd ed., pp. 132-156) Churchill Livingstone.

Davis, D.L., \& Walker, K. (2011). Case-loading midwifery in New Zealand: Bridging the normal/abnormal divide "with woman." Midwifery, 27, 46-52. https://doi.org/10.1016/j.midw.2009.09.007

Davison, C., Hauck, Y. L., Bayes, S. J., Kuliukas, L. J., \& Wood, J. (2015). The relationship is everything: Women's reasons for choosing a privately practising midwife in Western Australia. Midwifery, 31, 772-778. https://doi.org/10.1016/j.midw.2015.04.012

De Jonge, A., Stuijt, R., Eijke, I., \& Westerman, M. J. (2014). Continuity of care: What matters to women when they are referred from primary to secondary care during labour? A qualitative interview study in the Netherlands. BMC Pregnancy and Childbirth, 14(103). https://doi.org/10.1186/1471-2393-14103

Donnellan-Fernandez, R. E., Creedy, D. K., \& Callander, E. J. (2018). Costeffectiveness of continuity of midwifery care for women with complex pregnancy: A structured review of the literature. Health Economics Review, pp. 1-16. https://doi.org/10.1186/s13561-018-0217-3

Dove, S., \& Muir-Cochrane, E. (2014). Being safe practitioners and safe mothers: A critical ethnography of continuity of care midwifery in Australia. Midwifery, 30, 1063-1072. https://doi.org/10.1016/j.midw.2013.12.016

Eddy, A., \& Campbell, N. (2019). The frameworks that support continuity of midwifery care. In K. Guilliland,\& L. Dixon (Ed.), Continuity of Midwifery 
Care in Aotearoa New Zealand: Partnership in action (pp. 26-33). New Zealand College of Midwives.

Enkin, M. (2006). Beyond evidence: The Complexity of Maternity Care. Birth, 33(4), 265-269.

Forster, D. A., McLachlan, H. L., Davey, M. A., Biro, M. A., Farrell, T., Gold, L., ... Waldenström, U. (2016). Continuity of care by a primary midwife (caseload midwifery) increases women's satisfaction with antenatal, intrapartum and postpartum care: Results from the COSMOS randomised controlled trial. BMC Pregnancy and Childbirth.

https://doi.org/10.1186/s12884-016-0798-y

Freeman, G.K., Woloshynowych, M., Baker, R., Boulton, M., Gutherie, B., Car, J., Haggerty, J., \& Tarrant, C. (2007). Continuity of care 2006: what have we learned since 2000 and what are policy imperatives now?

Guilliland, K., \& Pairman, S. (1995). The Midwifery Partnership: A Model for Practice. Monograph Series;95/1. Department of Nursing and Midwifery Victoria University of Wellington.

Guilliland, K., \& Tracy, S. (2015). Australia and New Zealand midwifery and Maternity Services. In S. Pairman, S., Pincombe, J., Thorogood, C., \& Tracy (Ed.), Midwifery Preparation for practice (3rd ed., pp. 3-38).

Churchill Livingstone.

Haggerty, J. L., Reid, R. J., Freeman, G. K., Starfield, B. H., Adair, C. E., \& McKendry, R. (2003). Continuity of care: A multidisciplinary review. British Medical Journal.

Hauck, Y., Nathan, E., Ball, C., Hutchinson, M., Somerville, S., Hornbuckle, J., \& Doherty, D. (2018). Women's reasons and perceptions around planning a homebirth with a registered midwife in Western Australia. Women and Birth. https://doi.org/10.1016/j.wombi.2018.11.017

Holness, N. (2018). High-Risk Pregnancy. Nursing Clinics of North America. https://doi.org/10.1016/j.cnur.2018.01.010

Homer, C. S. E. (2006). Challenging midwifery care, challenging midwives and 
challenging the system. Women and Birth.

https://doi.org/10.1016/j.wombi.2006.07.002

Homer, C. S., Leap, N., Edwards, N., \& Sandall, J. (2017). Midwifery continuity of carer in an area of high socio-economic disadvantage in London: A retrospective analysis of Albany Midwifery Practice outcomes using routine data (1997-2009). Midwifery, 48.

https://doi.org/10.1016/j.midw.2017.02.009

Hunter, B., Berg, M., Lundgren, I., Ólafsdóttir, Ó. Á., \& Kirkham, M. (2008).

Relationships: The hidden threads in the tapestry of maternity care.

Midwifery. https://doi.org/10.1016/j.midw.2008.02.003

Jenkins, M. G., Ford, J. B., Todd, A. L., Forsyth, R., Morris, J. M., \& Roberts, C.

L. (2015). Women's views about maternity care: How do women

conceptualise the process of continuity? Midwifery, 31, 25-30.

https://doi.org/10.1016/j.midw.2014.05.007

Kennedy, H. P., Shannon, M. T., Chuahorm, U., \& Kravetz, M. K. (2004). The landscape of caring for women: A narrative study of midwifery practice. Journal of Midwifery and Women's Health.

https://doi.org/10.1016/j.jmwh.2003.09.015

Kim, H., Sefeik, J.S., \& Bradway, C. (2017). Characteristics of Qualitative Descriptive Studies: A Systematic Review. Research in Nursing \& Health, 40, 23-42. https://doi.org/10.1002/nur.21768

Kuliukas, L., Duggan, R., Lewis, L., \& Hauck, Y. (2016). Women's experience of intrapartum transfer from a Western Australian birth centre co-located to a tertiary maternity hospital. BMC Pregnancy and Childbirth, 16(33). https://doi.org/10.1186/s12884-016-0817-z

Lee, S., Ayers, S., \& Holden, D. (2014). A metasynthesis of risk perception in women with high risk pregnancies. Midwifery. https://doi.org/10.1016/j.midw.2013.04.010

Lee, S., Ayers, S., \& Holden, D. (2015). Risk perception and choice of place of birth in women with high risk pregnancies: A qualitative study. Midwifery. https://doi.org/10.1016/j.midw.2016.03.008 
Lee, S., Holden, D., \& Ayers, S. (2016). How women with high risk pregnancies use lay information when considering place of birth: A qualitative study. Women and Birth, 38, 42-48. https://doi.org/10.1016/j.wombi.2015.07.010

Lewis, M., Jones, A., \& Hunter, B. (2017). Women's Experience of Trust Within the Midwife-Mother Relationship. International Journal of Childbirth, 7(1), 40-52. https://doi.org/10.1891/2156-5287.7.1.40

Liamputtong, P. (2014). The Science of words and the Science of Numbers: Research Methods as Foundations for Evidence- based Practice in Health. In P. Liamputtong (Ed.), Research Methods in Health: Foundations for evidence-based practice. (2nd ed., pp. 3-22). Oxford University Press.

McLachlan, H. L., Forster, D. A., Davey, M. A., Farrell, T., Gold, L., Biro, M. A., ... Waldenström, U. (2012). Effects of continuity of care by a primary midwife (caseload midwifery) on caesarean section rates in women of low obstetric risk: The COSMOS randomised controlled trial. BJOG: An International Journal of Obstetrics and Gynaecology, 119, 1483-1492. https://doi.org/10.1111/j.1471-0528.2012.03446.x

Miller, S. \& Dahlen, H. (2019). Working in collaboration. In S. Pairman, S. Tracy, H. Dahlen, L. Dixon (Eds.), Midwifery Preparation for practice (4th ed., pp. 334-346). Churchill Livingstone.

Miller, S. \& Wilkes, L. (2015). Working in Partnership. In S. Pairman, J. Pincombe, C. Thorogood, S. Tracy, (Eds.), Midwifery Preparation for practice (3rd ed., pp. 412-428). Churchill Livingstone.

Miller,S.,\& Bear, R. (2019). Midwifery partnership. In S. Pairman, S. Tracy, H. Dahlen, L. Dixon (Eds.), Midwifery Preparation for practice 4e (4th ed., pp. 299-333). Churchill Livingstone.

Ministry for Women. (2018). Mothers and their babies Women's experiences. Retrieved from https://women.govt.nz/sites/public_files/Mothers and their babies Women's experiences.pdf Ministry of Health. (2012). Guidelines for Consultation with Obstetric and Related Medical Services (Referral Guidelines). Author. 
Ministry of Health. (2019a). National Maternity Monitoring Group. Retrieved from https://www.health.govt.nz/our-work/life-stages/maternityservices/national-maternity-monitoring-group

Ministry of Health. (2019b). New Zealand Maternity Clinical Indicators 2017. Retrieved from 2019 website: https://www.health.govt.nz/publication/newzealand-maternity-clinical-indicators-2017

Ministry of Health. (2019c). Report on Maternity 2017. Retrieved from https://www.health.govt.nz/publication/report-maternity-2017 Morton, S. M. B., Atatoa Carr, P. E., Grant, C. C., Berry, S. D., Marks, E. J., Chen, X. M-H., Lee, A. C. (2014). Growing up in New Zealand :A longitudinal study of New Zealand children and their families. Vulnerability Report 1: Exploring the definition of vulnerability for Children in their first 1000 days. Retrieved from ISSN 2253-251X

Nagle, C., Skouteris, H., Hotchin, A., Bruce, L., Patterson, D., \& Teale, G. (2011). Continuity of midwifery care and gestational weight gain in obese women: A randomised controlled trial. BMC Public Health. https://doi.org/10.1186/1471-2458-11-174

National Health System. (2017). Implementing Better Births: Continuity of carer. Retrieved from https://www.england.nhs.uk/wpcontent/uploads/2017/12/implementing-better-births.pdf

National Maternity Perinatal Audit Project team. (2017). National Maternity and Perinatal Audit: organizational report 2017. Retrieved from https://maternityaudit.org.uk/downloads/NMPA organisational report 2017.pdf

New Zealand College of Midwives. (2015). Midwives Handbook for Practice. (5th ed.). New Zealand College of Midwives.

Pairman, S. \& McAra- Couper, J. (2015). Theoretical frameworks for midwifery practice. In S. Pairman, J. Pincombe, C.Thorogood, \& S. Tracy (Eds.), Midwifery Preparation for practice ( $3^{\text {rd }}$ ed. pp383-411). Churchill Livingstone 
Perdok, H., Jans, S., Verhoeven, C., van Dillen, J., Batenburg, R., Mol, B. W., ... de Jonge, A. (2016). Opinions of professionals about integrating midwife- and obstetrician-led care in The Netherlands. Midwifery. https://doi.org/10.1016/j.midw.2016.03.011

Perdok, H., Mokkink, L., van Dillen, J., Westerneng, M., Jans, S., Mol, B. W., \& de Jonge, A. (2014). Opinions of maternity care professionals about integration of care during labor for "moderate risk" indications: A delphi study in the Netherlands. Birth, 41(2). https://doi.org/10.1111/birt.12102

Perriman, N., Davis, D. L., \& Ferguson, S. (2018). What women value in the midwifery continuity of care model: A systematic review with metasynthesis. Midwifery, 62, 220-229.

https://doi.org/10.1016/j.midw.2018.04.011

Priday, A., \& McAra-Couper, J. (2016). A Successful Midwifery Model for a High Deprivation Community in New Zealand: A Mixed Methods Study. International Journal of Childbirth. https://doi.org/10.1891/2156-5287.6.2.78

Ramcharan, P. (2014). What is Ethical Research? In P. Liamputtong (Ed.), Research Methods in Health: Foundations for evidence-based practice. (2nd ed., pp. 24-36). Oxford University Press.

Rayment-Jones, H., Murrells, T., \& Sandall, J. (2015). An investigation of the relationship between the caseload model of midwifery for socially disadvantaged women and childbirth outcomes using routine data - A retrospective, observational study. Midwifery, 31, 409-417. https://doi.org/10.1016/j.midw.2015.01.003

Sandall, J., Coxon, K., Mackintosh, N., Rayment-Jones, H. and Page, L. (2016). Relationships:the pathway to safe, high-quality maternity care. Retrieved from https://www.gtc.ox.ac.uk/wp-content/uploads/2018/12/skp_report.pdf

Sandall, J, Soltani, H., Gates, S., Shennan, A., \& Devane, D. (2016). Midwifeled continuity models versus other models of care for childbearing women ( Review ) summary of findings for the main comparison. Cochrane Database of Systematic Reviews.

https://doi.org/10.1002/14651858.CD004667.pub5.www.cochranelibrary.co 
Sandall, Jane. (2014). The contribution of continuity of midwifery care to high quality maternity care. Royal College of Midwives, 16. Retrieved from https://www.rcm.org.uk/sites/default/files/Continuity of Care A5 Web.pdf

Sandall, Jane, Soltani, S., Gates, S., Shennan, A., \& Devane, D. (2016). Cochrane Database of Systematic Reviews Midwifeled continuity models versus other models of care for childbearing women (Review). The Cochrane Database of Systematic Reviews. https://doi.org/10.1002/14651858.CD004667.pub5

Sandelowski, M. (2000). Whatever happened to qualitative description? Research in Nursing \& Health, 23, 334-340. https://doi.org/10.1002/1098240x(200008)23:4<334::aid-nur9>3.0.co;2-g

Sandelowski, M. (2010). What's in a name? Qualitative description revisited. Research in Nursing and Health, 33, 77-84. https://doi.org/10.1002/nur.20362

Skinner, J. \& Dahlen, H. (2015). Risk,fear and safety. In S. Pairman, J., Pincombe, C. Thorogood, \& S. Tracy (Eds.), Midwifery Preparation for practice (3rd ed., pp. 87-102). Elsevier.

Skinner, J. (2011). Being with women in risk. New Zealand College of Midwives, (45), 17-20.

Skinner, J. P., \& Foureur, M. (2010). Consultation, Referral, and Collaboration Between Midwives and Obstetricians: Lessons From New Zealand. Journal of Midwifery and Women's Health, 55(1), 28-37. https://doi.org/10.1016/j.jmwh.2009.03.015

Skinner, Joan, \& Maude, R. (2015). The tensions of uncertainty: Midwives managing risk in and of their practice. Midwifery, 38, 35-41. https://doi.org/10.1016/j.midw.2016.03.006

Thorogood, C. (2015). Models of health. In S. Pairman, J. Pincombe, C. Thorogood \& S. Tracy, (Eds.), Midwifery Preparation for practice (3rd ed, pp. 56-71). Churchill Livingstone. 
Tracy, S. K., Hartz, D., Hall, B., Allen, J., Forti, A., Lainchbury, A., ... Kildea, S. (2011). A randomised controlled trial of caseload midwifery care: M@NGO (Midwives @ New Group practice Options). BMC Pregnancy and Childbirth. https://doi.org/10.1186/1471-2393-11-82

Tracy, S. K., Hartz, D. L., Tracy, M. B., Allen, J., Forti, A., Hall, B., ... Kildea, S. (2013). Caseload midwifery care versus standard maternity care for women of any risk: M@NGO, a randomised controlled trial. The Lancet, 382, 1723-1732. https://doi.org/10.1016/S0140-6736(13)61406-3

Vaismoradi, M., Turunen, H., \& Bondas, T. (2013). Content analysis and thematic analysis: Implications for conducting a qualitative descriptive study. Nursing and Health Sciences, pp. 398-405.

https://doi.org/10.1111/nhs.12048

Weston, K. (2014). Meeting the needs of birthing women. Kai Tiaki Nursing New Zealand, 20(2), 28-29.

Wickham, S. (2015). Being clear about continuity. The Practising Midwife, July/Augus, 42-43.

Wilkes, E., Gamble, J., Adam, G., \& Creedy, D. K. (2015). Reforming maternity services in Australia: Outcomes of a private practice midwifery service. Midwifery. https://doi.org/10.1016/j.midw.2015.05.006

Zondag L., Cadee, F. de Gues, M. (2017). Midwifery in the Netherlands. Koninklijke Nederlandse Organisatie van Verloskundigen (KNOV). 